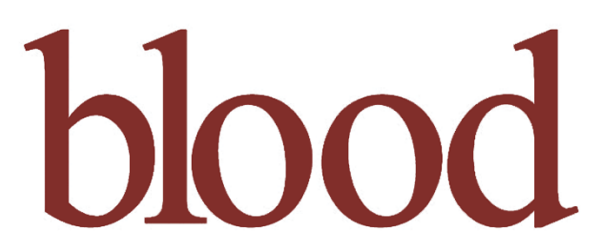

2007 109: 2634-2642

Prepublished online Nov 7, 2006;

doi:10.1182/blood-2006-06-030411

\title{
In vitro and in vivo arterial differentiation of human multipotent adult progenitor cells
}

Xabier L. Aranguren, Aernout Luttun, Carlos Clavel, Cristina Moreno, Gloria Abizanda, Miguel A. Barajas, Beatriz Pelacho, Maialen Uriz, Miriam Araña, Ana Echavarri, Mario Soriano, Enrique J. Andreu, Juana Merino, Jose Manuel Garcia-Verdugo, Catherine M. Verfaillie and Felipe Prósper

Updated information and services can be found at:

http://bloodjournal.hematologylibrary.org/cgi/content/full/109/6/2634

Articles on similar topics may be found in the following Blood collections:

Hematopoiesis and Stem Cells (2485 articles)

Stem Cells in Hematology (166 articles)

Information about reproducing this article in parts or in its entirety may be found online at:

http://bloodjournal.hematologylibrary.org/misc/rights.dtl\#repub_requests

Information about ordering reprints may be found online at:

http://bloodjournal.hematologylibrary.org/misc/rights.dtl\#reprints

Information about subscriptions and ASH membership may be found online at:

http://bloodjournal.hematologylibrary.org/subscriptions/index.dtl

Blood (print ISSN 0006-4971, online ISSN 1528-0020), is published semimonthly by the American Society of Hematology, $1900 \mathrm{M} \mathrm{St}$, NW, Suite 200, Washington DC 20036.

Copyright 2007 by The American Society of Hematology; all rights reserved.

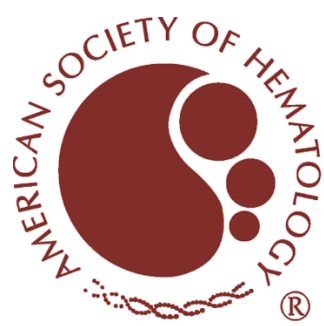




\title{
In vitro and in vivo arterial differentiation of human multipotent adult progenitor cells
}

\author{
Xabier L. Aranguren, ${ }^{1}$ Aernout Luttun, ${ }^{2,3}$ Carlos Clavel, ${ }^{1}$ Cristina Moreno, ${ }^{1,4}$ Gloria Abizanda, ${ }^{1}$ Miguel A. Barajas,${ }^{1,2}$ \\ Beatriz Pelacho, ${ }^{2}$ Maialen Uriz, ${ }^{1}$ Miriam Araña, ${ }^{1}$ Ana Echavarri, ${ }^{1}$ Mario Soriano, ${ }^{5}$ Enrique J. Andreu, ${ }^{1}$ Juana Merino, ${ }^{4}$ \\ Jose Manuel Garcia-Verdugo, ${ }^{5}$ Catherine M. Verfaillie, ${ }^{2}$ and Felipe Prósper ${ }^{1}$
}

${ }^{1}$ Hematology Service and Cell Therapy, Clínica Universitaria, Foundation for Applied Medical Research, Division of Cancer, University of Navarra, Pamplona, Spain; ${ }^{2}$ Stem Cell Institute, University of Minnesota Medical School, Minneapolis; ${ }^{3}$ Center for Molecular and Vascular Biology, Catholic University of Leuven, Belgium; ${ }^{4}$ mmunology Service, Clínica Universitaria, University of Navarra, Pamplona, Spain; ${ }^{5}$ Department of Cell Biology, Instituto Cavanilles, University of Valencia, Spain

\begin{abstract}
Many stem cell types have been shown to differentiate into endothelial cells (ECs); however, their specification to arterial or venous endothelium remains unexplored. We tested whether a specific arterial or venous EC fate could be induced in human multipotent adult progenitor cells (hMAPCs) and $\mathrm{AC}_{133^{+}}$cells $\left(\mathrm{hAC} 133^{+}\right)$. In vitro, in the presence of VEGF $_{165}$, hAC133+ cells only adopted a venous and microvascular EC phenotype, while
\end{abstract}

hMAPCs differentiated into both arterial and venous ECs, possibly because hMAPCs expressed significantly more sonic hedgehog (Shh) and its receptors as well as Notch 1 and 3 receptors and some of their ligands. Accordingly, blocking either of those pathways attenuated in vitro arterial EC differentiation from hMAPCs. Complementarily, stimulating these pathways by addition of Delta-like 4 (DIl-4), a Notch ligand, and Shh to VEGF 165 further boosted arterial differentiation in hMAPCs both in vitro and in an in vivo Matrigel model. These results represent the first demonstration of adult stem cells with the potential to be differentiated into different types of ECs in vitro and in vivo and provide a useful human model to study arteriovenous specification. (Blood. 2007;109:2634-2642)

(C) 2007 by The American Society of Hematology

\section{Introduction}

The vascular system is a bipolar complex network of arteries that transport oxygen-rich blood to all tissues and veins that bring oxygendeprived blood back to the heart. ${ }^{1}$ Because of this bipolar set-up, arteries and veins feature anatomic and physiological differences. Unlike venous endothelium, arterial endothelium is surrounded by several layers of smooth muscle cells (SMCs), separated by elastic laminae, and embedded in a thick layer of fibrillar collagen. ${ }^{2}$ Moreover, both vessel types have a differential susceptibility to atherosclerotic disease, possibly due to exposure to different levels of shear stress. Arterial and venous endothelial cells (ECs) also have a distinct molecular signature, and such molecular specification occurs before the onset of blood flow. ${ }^{3}$ Indeed, arteriovenous (AV) specification of ECs is accomplished early in development and is associated with the expression of a specific complement of factors: venous endothelium is characterized by the expression of EphB $4,{ }^{4}$ Lefty- $1,{ }^{5}$ Lefty- $2,{ }^{5}$ COUP-TFII, ${ }^{6}$ and MYO1- $\beta,{ }^{5}$ and arterial ECs express high levels of Notch 1 and $4,{ }^{7}$ Dll- $4,{ }^{8}$ EphrinB1 and EphrinB2, ${ }^{4}$ Jagged-1 and -2, ${ }^{7}$ connexin-40, and Hey-2 (gridlock zebrafish ortholog). ${ }^{9,10}$ Studies in Xenopus, zebrafish, and mice have revealed that, besides blood flow, ${ }^{11}$ vessel-intrinsic cues and-later in development-signals from outside the vasculature ${ }^{12,13}$ are implicated in defining arterial or venous fate such as members of the TGF- $\beta$ pathway, ${ }^{14,15}$ VEGF isoforms, ${ }^{13,16-18}$ neuropilins,,${ }^{17}$ angiopoietins, ${ }^{19}$ the Notch pathway, ${ }^{7,90-22}$ the patched pathway, ${ }^{20}$ and COUP-TFII, a member of the orphan nuclear receptor superfamily. ${ }^{6}$

Although it has been shown that some of these pathways are well conserved from zebrafish to mouse, less information is available on whether they have a similar role in humans. Because these molecular differences between arterial and venous ECs exist independently of blood flow and some of these factors work in an EC-intrinsic way, ${ }^{2}$ it should be possible to manipulate some or all of these to endow ECs with an arterial or venous fate. Consistent with this notion, recent studies have suggested that arterial markers can be induced in primary mature ECs. $., 13,21,23,24$

Many different stem cell populations, including bone marrow (BM) mononuclear cells, $\mathrm{AC} 33^{+}$endothelial progenitor cells, and embryonic stem cells have the potential to differentiate in vitro and in vivo into mature and functional ECs. ${ }^{4,25-28}$ We have recently described another stem cell population, multipotent adult progenitor cells (MAPCs), that differentiates into most somatic cell types, including functional ECs, in vitro and in vivo. ${ }^{29-33}$ The question of whether and how these stem cells can be coaxed into arterial or venous ECs has thus far not been addressed. In this study, we analyzed the in vitro and in vivo arterial and venous endothelial differentiation of human MAPCs (hMAPCs) and hAC133+ cells.

\section{Materials and methods}

Additional and extended descriptions of methods are included in Document S1 (available on the Blood website; see the Supplemental Materials link at the top of the online article).
Submitted June 21, 2006; accepted October 29, 2006. Prepublished online as Blood First Edition Paper, November 7, 2006; DOI 10.1182/blood-2006-06-030411.
The publication costs of this article were defrayed in part by page charge payment. Therefore, and solely to indicate this fact, this article is hereby marked "advertisement" in accordance with 18 USC section 1734.

() 2007 by The American Society of Hematology 


\section{Cell populations}

Samples were obtained after informed consent from donor or mother according to the guidelines from the Committee on the Use of Human Subjects in Research at the Clínica Universitaria, Pamplona, Spain. For hAC133+ cells, BM and umbilical cord blood mononuclear cells were separated by Ficoll Hypaque centrifugation (specific gravity, 1077; Sigma, St Louis, MO), and hAC133+ cells were selected using the autoMACS with the AC133 Isolation Kit (Miltenyi Biotec, Bergisch Gladbach, Germany). ${ }^{34}$ The purity of $\mathrm{hAC} 33^{+}$cells was more than $90 \%$ in all samples by flow cytometry. New hMAPC clones were established, based on protocols described previously, ${ }^{29-33}$ at the University of Navarra using BM from donors aged 18 to 54 years. BM mononuclear cells were depleted of CD45 and glycophorin A-positive cells using micromagnetic beads (Miltenyi Biotec) or directly after Ficoll-Paque. Characterization of hMAPCs was done by fluorescence-activated cell sorter (FACS) phenotyping, pluripotency marker expression analysis, and 3-lineage differentiation (Document S1, Figure S1, Table S1). Primary human umbilical vein ECs (HUVECs) and human umbilical artery ECs (HUAECs) were prepared in-house from human umbilical cords.

\section{Endothelial differentiation/specification of $\mathrm{hAC} 133^{+}$cells and hMAPCs}

Human AC133+ cells. For hAC133+ cells, a total of $10^{5} / \mathrm{cm}^{2}$ were plated on fibronectin $(50 \mu \mathrm{g} / \mathrm{mL})$-coated culture vessels in IMDM (Gibco BRL, Carlsbad, CA) supplemented with $20 \%$ fetal calf serum (FCS) (Gibco BRL), $50 \mathrm{ng} / \mathrm{mL} \mathrm{VEGF}_{165}$ (R\&D Systems, Minneapolis, MN), $10 \mathrm{ng} / \mathrm{mL}$ bFGF (Sigma), and $1 \%$ penicillin/streptomycin. Cultures were maintained by media exchange every 4 to 5 days.

Human MAPCs. The hMAPCs were plated at $30 \times 10^{3}$ to $40 \times 10^{3} /$ $\mathrm{cm}^{2}$ in growth media: 58\% low-glucose DMEM (Gibco BRL), $40 \%$ MCDB-201 (Sigma), 2\% FCS (Biochrom, Cambridge, United Kingdom), ITS +1 (Sigma), $10^{-8} \mathrm{M}$ dexamethasone (Sigma), $10^{-4} \mathrm{M}$ ascorbic acid 2-phosphate (Sigma), 1\% penicillin/streptomycin (Gibco BRL), and 10 $\mathrm{ng} / \mathrm{mL}$ each of PDGF-BB and EGF during 24 hours, and then media were exchanged with the same media without FCS, EGF, and PDGF-BB but now with $100 \mathrm{ng} / \mathrm{mL} \mathrm{VEGF}_{165}$. Media were changed every 4 to 5 days. Arterial-specific differentiation was boosted by addition of different combinations of the following growth factors: VEGF $_{165}$ in different combinations with Dll-4, Jagged-1, or Shh (all from R\&D Systems at 100 $\mathrm{ng} / \mathrm{mL}$ ). Blocking of patched and Notch pathways was performed using cyclopamine $^{35}$ (Biomol, Plymouth Meeting, PA) at $5 \mu \mathrm{M}$ (added every 4 to 5 days with medium change) and $1 \mu \mathrm{M} \gamma$-secretase inhibitor L-685458 (Bachem, King of Prussia, PA), ${ }^{36}$ respectively.

\section{FACS analysis}

For fluorescence-activated cell sorter (FACS) analysis, cells were detached with $0.05 \%$ trypsin-EDTA and washed with phosphate-buffered saline (PBS). The following antibodies were used: CD31-PE, CD34-APC, $\alpha_{V} \beta_{3^{-}}$ PE, CD73-PE, CD45-PerCP, CD90-APC, HLA-DR-PE, HLA-DP-PE, HLA-DQ-PE, HLA-A-PE, HLA-B-PE, HLA-C-PE, CD44-PE, CD13-PE, CD36-FITC, CD16+CD56-PE, CD3-FITC, CD19-APC, CD11B-PE, CD11C-APC, CD14-APC, CD14 FITC (all from BD PharMingen, San Diego, CA), CD105-PE (Ancell, Bayport, MN), and CD133/1-PE and CD133/1APC (Miltenyi Biotec), and their corresponding isotype controls (all from BD PharMingen). From 50000 to 200000 cells were incubated with primary antibody for 15 minutes in the dark at room temperature. Cells were fixed with $4 \%$ paraformaldehyde at $4{ }^{\circ} \mathrm{C}$. Syto was used to determine cell viability when necessary. Samples were analyzed using a FACS Calibur (BD PharMingen) cell sorter and Cellquest (BD PharMingen) software.

\section{Immunofluorescent and histochemistry staining and analysis}

A list of primary antibodies is provided in Table S2. Secondary antibodies coupled to FITC or PE were from Molecular Probes (Eugene, OR). For immunofluorescent staining, samples were fixed with $4 \%$ paraformaldehyde at $20^{\circ} \mathrm{C}$ and, in case of intracellular molecules, permeabilized with $0.1 \%$ Triton X-100. Blocking solution consisted of PBS, $1 \%$ bovine serum albumin, and $10 \%$ donkey serum. Primary antibodies were diluted in blocking solution and applied overnight at $4^{\circ} \mathrm{C}$. After incubation, nonspecific binding was washed with a solution of PBS and $0.1 \%$ Tween 20 . Secondary antibody at a dilution 1:1000 in PBS was applied for 1 hour at $4^{\circ} \mathrm{C}$. Nonadherent antibody was washed with PBS and $0.1 \%$ Tween 20 , after which samples were mounted using DAPI (Vector Laboratories, Burlingame, CA) or TO-PRO-3 iodide (Molecular Probes, Leiden, The Netherlands) as nuclear marker. For controls, cells were labeled with unspecific immunoglobulins (Santa Cruz Biotechnology, Santa Cruz, CA) followed by incubation with the secondary antibody. For immunohistochemistry staining, the Envision (DAKO, Glostrup, Denmark) and ABC (Vector Laboratories) systems were used. Sirius red $^{37}$ and orcein ${ }^{38}$ staining were performed as described. To quantify the percentage of cultured cells expressing arterial or venous markers, the number of positive cells in 20 randomly selected fields were scored and divided by the total number of cells.

Images were generated using a Zeiss microscope (Zeiss, Jena, Germany) connected to a monochrome fluorescence camera (Coolsnap SF; Photometrics, _. Germany) and a CCD camera (SPOT; Diagnostic Instruments, Sterling Heights, MI), equipped with $20 \times / 0.75$ NA dry, $40 \times / 0.75$ NA dry, and $63 \times / 1.40$ NA oil objectives (Zeiss). Morphometric analyses were performed using MetaMorph software (version 6.3r6; Molecular Devices, Downington, PA). Immersion oil was purchased from Zeiss.

\section{RNA isolation and real-time and quantitative RT-PCR}

Total RNA was obtained using the RNeasy Mini extraction kit (Qiagen, Hilden, Germany) according to the manufacturer's instructions. A more detailed description of methods and the primers used for reverse transcriptase-polymerase chain reaction (RT-PCR) and real-time PCR are shown in Document S1 and Table S3, respectively.

\section{In vitro EC functional tests}

To analyze acetylated-LDL uptake, cells were washed and $10 \mu \mathrm{g} / \mathrm{mL}$ acetylated-LDL-DiI (Biomedical Technologies, Stoughton, MA) was added in IMDM or MAPC differentiation medium (described under "Human MAPCs," above). Cells were incubated for 2 hours at $37^{\circ} \mathrm{C}$, washed, fixed, and viewed under a fluorescent microscope using DAPI as nuclear marker. For the in vitro Matrigel assay, $1 \mathrm{~mm}$ cold $\left(4^{\circ} \mathrm{C}\right)$ Matrigel (BD Pharmingen) was incubated for 30 minutes at $37^{\circ} \mathrm{C}$. After gelification, $30 \times 10^{3}$ to $50 \times 10^{3}$ cells differentiated for 14 days were plated in differentiation media on Matrigel. After 24 to 48 hours, tube formation was analyzed.

\section{Electron microscopy}

For ultrastructural studies, samples were washed in PBS and fixed with 2\% glutaraldehyde. Samples were postfixed with $1 \%$ osmium, rinsed, dehydrated, and embedded in Araldite (Fluka, Buchs, Switzerland). Semithin sections $(1.5 \mu \mathrm{m})$ were cut with a diamond knife and stained lightly with $1 \%$ toluidine blue. Then, semithin sections were reembedded in an araldite block and detached from the glass slide by repeated freezing (liquid nitrogen) and thawing. The block with semithin sections was cut into ultrathin (50 to $70 \mathrm{~nm}$ ) sections, stained with lead citrate, and examined under a Jeol (Tokyo, Japan) JEM-1010 electron microscope.

\section{ELISA}

To assess cytokine production of undifferentiated cells, hMAPCs were plated in triplicate at $30 \times 10^{3}$ to $40 \times 10^{3} / \mathrm{cm}^{2}$ at day 0 in cytokine-less expansion media, and supernatant was collected 60 hours later and frozen. To assess cytokine production in differentiated cells, cells were plated in triplicate for endothelial differentiation as described above and media were collected after 7 and 14 days and frozen. Enzyme-linked immunosorbent assay (ELISA) kits were from R\&D Systems, and the procedure was performed according to the manufacturer's recommendations. 


\section{In vivo Matrigel model}

For the in vivo Matrigel plug assay, 10-week-old nude mice were injected subcutaneously in the back with $0.5 \mathrm{~mL}$ cold growth factor-reduced Matrigel containing $300 \mathrm{ng} / \mathrm{mL} \mathrm{VEGF}_{165}$ alone, or $300 \mathrm{ng} / \mathrm{mL} \mathrm{VEGF}_{165}+$ $100 \mathrm{ng} / \mathrm{mL}$ Shh $+100 \mathrm{ng} / \mathrm{mL}$ Dll-4, combined or not with $0.5 \times 10^{6}$ undifferentiated hMAPCs or hAC133 ${ }^{+}$cells (unlabeled or labeled with carboxyfluorescein succinimidyl ester [CFSE; Molecular Probes] or Resovist [Schering, Berlin, Germany] as described ${ }^{39}$ ). In some animals, $0.1 \times 10^{6}$ or $2.5 \times 10^{6}$ cells were injected. Ten days after injection, animals were perfusion fixed and Matrigel plugs were removed and processed for paraffin or OCT embedding. Tissue sections were examined and photographed under a fluorescence microscope (Zeiss) or a confocal microscope. Ultrastructural analysis was performed as described above. In vivo live imaging was performed under anesthesia using a Leica (Weztlar, Germany) dissection microscope.

\section{Results}

\section{Isolation and qualification of hMAPCs}

For the current studies, 8 new clones of hMAPCs very similar in their characteristics were used. They were established at the University of Navarra using methods as previously described ${ }^{32,33}$ and maintained for more than 50 to 80 population doublings (Table $\mathrm{S} 1)$. The phenotype of most cells within these clones was $\mathrm{CD} 90^{+}$,

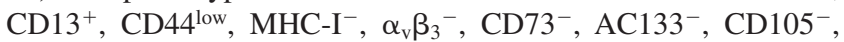
$\mathrm{MHC}_{-} \mathrm{II}^{-}, \mathrm{CD}^{-} 6^{-}, \mathrm{CD}^{-} 5^{-}$, and $\mathrm{CD}^{-} 4^{-}$(Figure S1A), largely consistent with their initial characterization. ${ }^{33}$ RT-PCR demonstrated presence of the transcription factors Oct3/4, Rex-1, and nanog as well as hTERT (Figure S1B), and cells stained positive for SSEA-4, Oct3/4, and nanog but not SSEA-1 proteins (Figure S1C-F). We further qualified the cells by showing differentiation into mesodermal (ECs, Figures S2J-R and S3; SMCs, Figure S1G), endodermal (hepatocytes, Figure $\mathrm{S} 1 \mathrm{H}$ ), and ectodermal (neurons, Figure S1I) cell types.

\section{VEGF $_{165}$ induces $\mathrm{hAC}_{133^{+}}$cells and $\mathrm{hMAPCs}$ to differentiate into functional ECs}

First, we compared the ability of hMAPCs and cord blood- or $\mathrm{BM}$-derived $\mathrm{hAC} 133^{+}$cells, a cell population previously shown to be enriched for endothelial, neuronal, and hematopoietic progenitors, ${ }^{25,26}$ to differentiate into functional mature endothelium. Culture of $\mathrm{hAC} 33^{+}$cells in the presence of $\mathrm{VEGF}_{165}$ induced down-regulation of AC133 and hematopoietic markers CD45 and CD34 and up-regulation of mature EC markers, CD105 and $\alpha_{\mathrm{v}} \beta_{3}$ (Figure S2A-B), as described. ${ }^{26}$ Most of the cells (about $80 \%$; Table S4) in 21-day cultures (which we further designate "hAC133ECs") expressed von Willebrand factor (VWF), angiopoietin receptors Tie-1 and -2, and VEGF receptors 1 and 2 (Flt-1 and KDR, respectively) (Figure S2C-G) and were functional as demonstrated by acetylated-LDL uptake (Figure S2H; Table S4) and vascular tube formation on Matrigel (Figure S2I). A fraction (about $20 \%$ ) of $\mathrm{hAC} 33^{+}$cells differentiated to hematopoietic cells, indicated by coexpression of the $\mathrm{CD} 45^{+}$antigen and other myeloidmonocytic antigens (Figure S4). Unlike human EC controls, which mostly showed a stellate shape in culture (Figure S5), hAC133-ECs were mainly rounded (FigS2C-H). Most (more than 80\%) hMAPCs cultured in the presence of $\mathrm{VEGF}_{165}$ acquired EC markers, including KDR, Flt-1, Tie-1, Tie-2, CD105, VE-cadherin, CD31, VWF, and $\alpha_{v} \beta_{3}$, while expression of hematopoietic markers CD34 and CD45 was very low or absent (Figures S2J-P and S3; Table S4). The resultant hMAPC-ECs were functional as shown by
acetylated-LDL uptake (Figure S2Q; Table S4) and vascular tube formation on Matrigel (Figure S2R). While no SMC $\alpha$-actinpositive cells were observed in $\mathrm{hAC} 133^{+}$cell-derived cultures, hMAPCs gave rise to SMC $\alpha$-actin-positive cells representing 5\% of the differentiated cells (not shown). For hMAPCs, the increase in mRNA expression varied between different endothelial genes from 5-fold (CD31) to more than 600-fold (Flt-1) (Figure S3).

\section{VEGF $_{165}$ supports arterial differentiation of hMAPCs but not hAC133+ cells}

Studies in zebrafish and mice have suggested that VEGF $_{165}$ would be part of a cascade involving Shh, Notch, and EphrinB2 that induces arterial differentiation in vivo and that $\mathrm{VEGF}_{165}$ alone may be sufficient to induce an arterial phenotype in vivo. ${ }^{20,40}$ To study whether $\mathrm{VEGF}_{165}$ was able to support arterial EC differentiation from stem cells in vitro, we determined using quantitative (Q)-RTPCR and/or immunofluorescence if the arterial markers Hey-2, Dll-4, EphrinB2, and EphrinB1 and the venous marker EphB4 were expressed in hMAPC-ECs and hAC133-ECs generated in the presence of $\mathrm{VEGF}_{165}$. Low transcripts levels for arterial- and venous-specific genes were detected in either cell population before differentiation. In $\mathrm{hAC} 133^{+}$cells, $\mathrm{VEGF}_{165}$ treatment decreased arterial markers while venous markers remained stable. In contrast, $\mathrm{VEGF}_{165}$ treatment induced significant levels of the arterial markers Hey-2, Dll-4, EphrinB1, and EphrinB2 as well as the venous marker EphB4 in hMAPCs (Figures 1A and S6). Ten- to 100 -fold differences were observed in arterial gene expression between hAC133-ECs and hMAPC-ECs. At the protein level, determined by immunofluorescence, expression of arterial Hey-2 $\left(48.3 \% \pm 3.5 \%\right.$ of the cells were Hey $\left.2^{+}\right)$, EphrinB1 $(65.8 \% \pm 4 \%)$, and venous EphB4 (31.2\% $\pm 2.8 \%)$ was found in hMAPC-ECs at day 14 (Figure 1B-D), while no protein expression was detected at baseline (not shown). Interestingly, while most hAC133-ECs expressed CD36, suggesting a microvascular phenotype, hMAPCECs were mostly $\mathrm{CD}^{-} 6^{-}$, suggesting a macrovascular phenotype $^{41-43}$ (Figure 1E). Together, this suggests the ability of hMAPCs but not hAC133 ${ }^{+}$cells to differentiate into arterial ECs in addition to venous ECs.

\section{Notch/patched pathway members are differentially expressed in hMAPCs and hAC133+ cells}

Because AV specification during zebrafish and mouse embryogenesis is in large part mediated by Notch and Shh in a cell-intrinsic manner, ${ }^{2}$ we compared the expression of Notch and its ligands, Jagged and Dll, and Shh and its receptor patched in undifferentiated hMAPCs and hAC133+ cells by Q-RT-PCR. Expression of Shh was restricted to hMAPCs (Figure 2A), and the expression of its receptors patched 1 and patched 2 was significantly higher in hMAPCs compared with hAC133+ cells (Figure 2A). Likewise, Notch-1 was uniquely expressed in hMAPCs (Figure 2B), and Dll-3, Jagged-1, and Notch-3 were more highly expressed in hMAPCs than $\mathrm{hAC} 33^{+}$cells (Figure 2B), while Dll-1 and Notch-4 were expressed preferentially in $\mathrm{hAC} 133^{+}$cells (Figure 2B). Expression of Jagged-2, Notch-2, and Dll-4 was not significantly different between the 2 undifferentiated cell populations (Figure 2B). To determine whether the different response to VEGF $_{165}$ in hMAPCs and $\mathrm{hAC} \mathrm{h}^{+}$cells could be due to differences in VEGF receptor or endogenous VEGF $_{165}$ expression, we compared their expression levels by Q-RT-PCR. Baseline endogenous $\mathrm{VEGF}_{165}$ expression was similar in both cell populations as well as expression of Flt-1 and KDR (not shown). Thus, the 
Figure 1. VEGF 165 induces arterial specification of hMAPCs but not hAC133+ cells. (A) Q-RT-PCR for arterial (EphrinB1, DIl-4, Hey-2, EphrinB2) and venous markers (EphB4) on hAC133+ cell-derived ECs $(\square)$ or hMAPC-derived ECs (圆) at different time points $(0,7,14$, and 21 days) after the start of the differentiation process. While hMAPCs up-regulated arterial and venous markers during the differentiation process, $\mathrm{hAC}_{133^{+}}$cellderived ECs showed reduced arterial marker expression. Expression levels are presented as fold increase (in logarithmic scale) in comparison with baseline levels and were normalized by using GAPDH as housekeeping gene. The mRNA levels in undifferentiated hMAPCs were considered as 1. Expression between baseline levels (day 0) and day 7, 14, and 21 for each cell population was compared $\left({ }^{\star} P<.05\right.$; $\left.{ }^{\star \star} P<.01\right)$. (B-D) Immunofluorescent staining of hMAPC-derived ECs. After 14 days, hMAPCs were positive for arterial markers EphrinB1 (B), Hey-2 (C), and venous marker EphB4 (D) (see text for percentage of positive cells). A representative example from 3 different clones is shown. (E) Comparative expression, plotted as percentage of total number of cells, based on FACS analysis, of the microvascular-specific marker CD36 in hMAPC (圆) and hAC133 ${ }^{+}$ cell-derived ECs $(\square)\left({ }^{\star \star} P<.01\right.$ versus hMAPC-ECs). The mean ( \pm SEM) of $3(A)$ or $5(E)$ different experiments in triplicate is shown. Magnification $\times 40$.

A

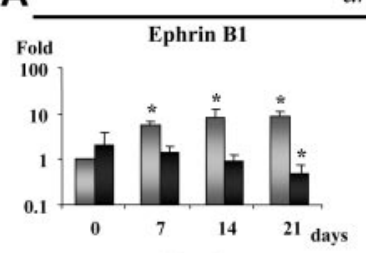

arterial
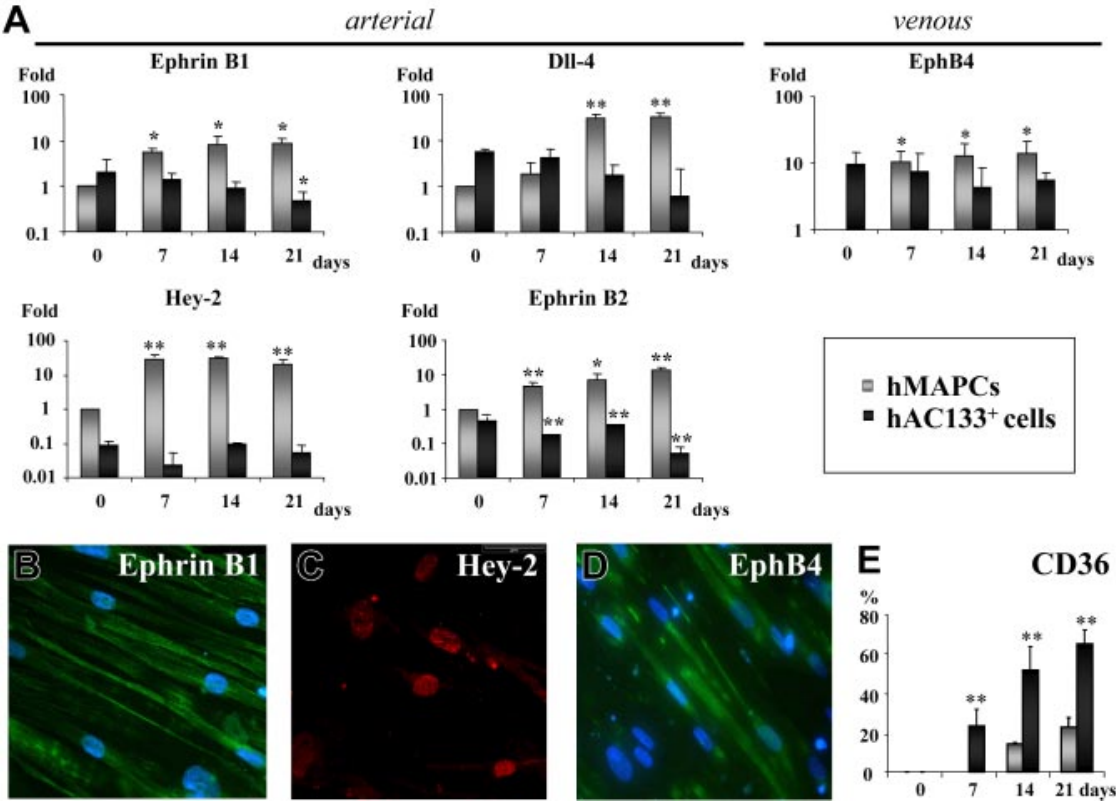

expression of Shh and patched, several of the Notch ligands, and receptors in hMAPCs may at least in part account for the ability of hMAPCs but not hAC133+ cells to differentiate along the arterial EC lineage.

\section{Shh or Notch pathway blocking attenuates arterial EC differentiation in hMAPCs}

To investigate the causal involvement of Notch and/or Shh/patched pathways in arterial EC differentiation from hMAPCs, we manipulated each of them separately. Specific blocking of Shh signaling by cyclopamine-mediated inhibition of the patched receptor complex $^{35}$ significantly decreased expression of arterial EC markers Hey-2, EphrinB1, and EphrinB2 and simultaneously slightly (but not statistically significant) increased expression of the venous marker EphB4 (Figure 3A). A more pronounced attenuation of arterial EC marker expression was observed by blocking the Notch pathway using an inhibitor for $\gamma$-secretase, essential for Notch receptor activation ${ }^{36}$ (Figure $3 \mathrm{~A}$ ). Compared with either inhibitor alone, combining cyclopamine and $\gamma$-secretase inhibitor further significantly decreased expression of Hey-2 $(P<.05)$ but not of EphrinB1 or EphrinB2 $(P>.05)$ (Figure 3A). These results suggest that arterial specification in hMAPCs in the presence of VEGF $_{165}$ is at least in part mediated by the patched and Notch pathways.

\section{Simultaneous Notch and patched activation boosts arterial EC fate in hMAPCs}

To further evaluate the role of Notch and patched in arterial specification of hMAPCs, we evaluated the effect of $\mathrm{VEGF}_{165}$ (alone or combined with either Dll-4 or Jagged-1) and Shh (alone or in combination) (Figure S6). Of all combinations tested, addition of Dll-4 and Shh most efficiently increased expression of Hey-2 along with down-regulation of venous marker EphB4, indicating a preferential differentiation toward arterial endothelium (Figures $3 \mathrm{~A}$ and S6). We analyzed the latter condition $\left(\mathrm{VEGF}_{165}+\mathrm{Shh}+\right.$ Dll-4) in more detail by examining the expression of additional arterial specific genes, showing that in addition to Hey-2, Jagged-2 and ALDH1A1 were also up-regulated, in agreement with previous work with HUVECs. ${ }^{5}$ Increased expression of arterial markers was associated with decreased levels of additional venous-specific Lefty-1 and Lefty-2 transcripts (Figure 3B). While Notch and

\section{A Patched pathway}

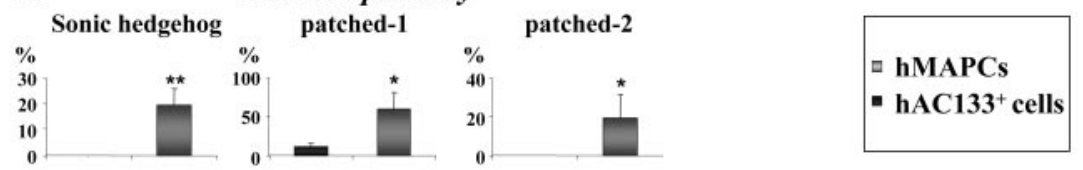

\section{B}
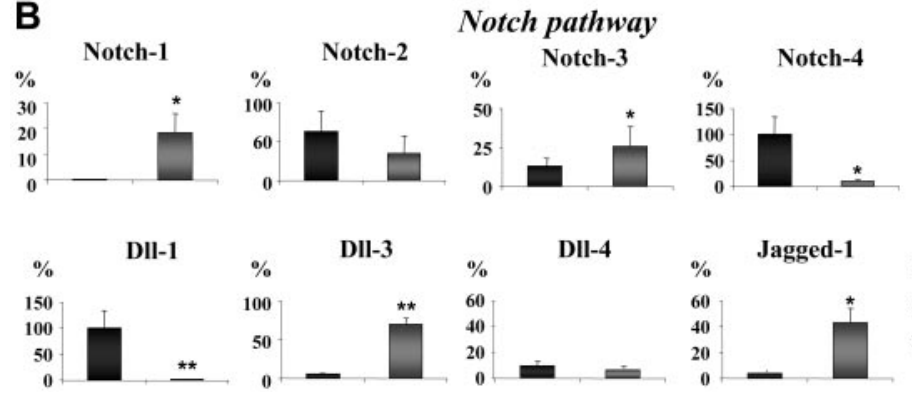

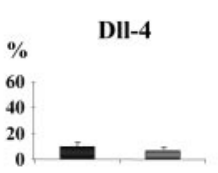

Figure 2. Notch and patched pathway members are differentially expressed in hMAPCs and $\mathrm{hAC} 133^{+}$cells. Q-RT-PCR analysis of members of the patched pathway (Shh, patched-1, and patched-2) (A) and the Notch pathway (Notch-1, $-2,-3$, and -4 and ligands DII- $1,-3,-4$, and Jagged-1 and -2) (B) known to be involved in AV specification. Note differences in expression (see "Results") between hMAPCs compared with hAC133+ cells. The mRNA levels in all panels are expressed in percentage versus a positive control (total RNA) and were normalized by using GAPDH as housekeeping gene. The mean ( \pm SEM) of 3 different experiments in triplicate is shown. ${ }^{*} P<.05$; ${ }^{* *} P<.01$ versus $\mathrm{hAC} 133^{+}$cells. 
A
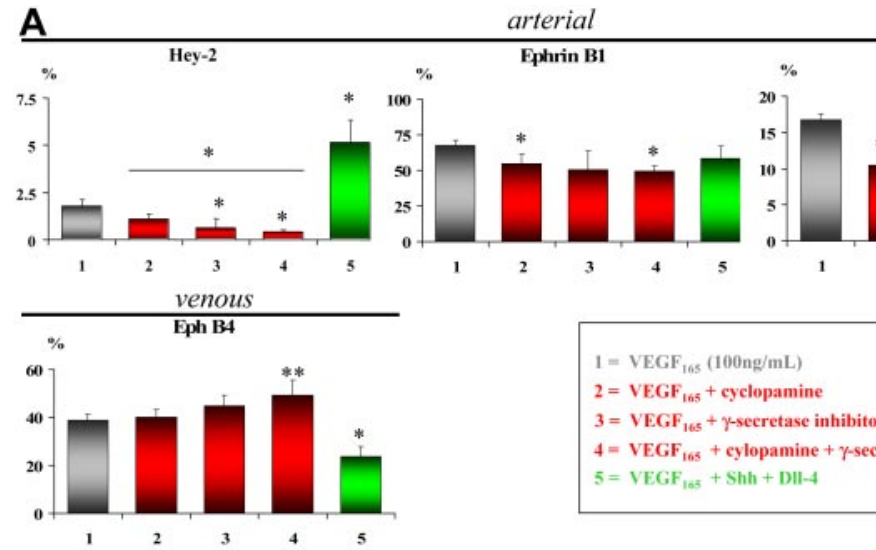

B

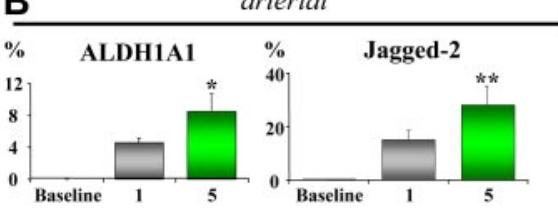

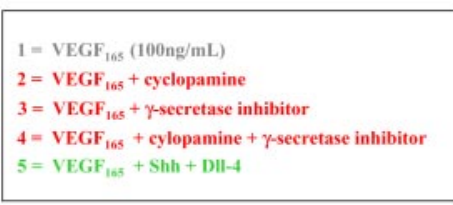

venous

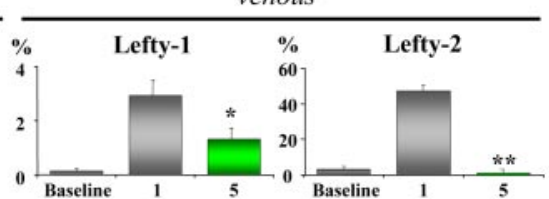

Figure 3. Blockage of Notch/patched pathway attenuates while stimulation increases arterial EC differentiation of hMAPCs. (A) Q-RT-PCR analysis for arterial (EphrinB1, Hey-2, and EphrinB2) and venous markers (EphB4) on hMAPC-derived ECs (gray bars) after 14 days of differentiation using blocking (red bars) or activating (green bars) treatments (as indicated in the box). Shh blocking, Notch blocking, or a combination of both significantly reduced expression of arterial EC markers paralleled by an increase in venous marker expression compared with VEGF 165 alone (gray bars). Conversely, addition of Shh and DII-4 to VEGF 165 further significantly increased expression of arterial marker Hey-2 while significantly decreasing venous marker EphB4. ${ }^{\star} P<.05 ;{ }^{* \star} P<.01$ versus VEGF VE5 $_{165}$ alone; ${ }^{*} P<.05$ condition 4 versus condition 2. (B) Q-RT-PCR analysis of additional arterial (ALDH1A1, Jagged-2) and venous markers (Lefty-1, Lefty-2) in hMAPC-derived ECs cultured in VEGF 165 alone (gray bars) or combined with Shh and DIl-4 (green bars). Note the significant up-regulation of arterial markers and simultaneous down-regulation of venous markers in the combination cocktail as compared with VEGF $_{165}$ alone. The mRNA levels in all panels are expressed as mean percentage of HUAECs (arterial markers) and HUVECs (venous markers) and were normalized using GAPDH as housekeeping gene. Baseline corresponds to undifferentiated hMAPCs. The mean ( \pm SEM) of 3 different experiments is shown. ${ }^{\star} P<.05 ;{ }^{\star *} P<.01$ versus $V_{E G F}$ alone.

patched activation enhanced arterial markers in hMAPCs, a similar effect was not observed in hAC133+ cells (Figure S6).

\section{Shh and DII-4 boost arterial EC differentiation of hMAPCs and arterial-like vessel growth in vivo}

To determine whether the same factors could also induce hMAPC differentiation into arterial endothelium in vivo, we injected $0.5 \times 10^{6}$ undifferentiated hMAPCs in growth factor-reduced Matrigel containing either $\mathrm{VEGF}_{165}$ ("standard media") or VEGF $_{165}+$ Shh + Dll-4 ("arterial media") under the skin of nude mice ( $n=6$ per group). To account for effects of the admixed cytokines on host cells, we also included the corresponding "cytokine-alone" groups. To track the cells following implantation, hMAPCs were labeled with CFSE or iron particles (Resovist) ${ }^{39,44}$ before injection. Irrespective of the cytokine cocktail used, localized areas of CFSE-labeled cells (Figure 4A) and single Resovistlabeled hMAPC-derived cells (Figure 4B) persisted for at least 10 days in the Matrigel plug as determined by in vivo live imaging and electron microscopy, respectively. Most implanted cells expressed (human) CD31 and (human) VE-cadherin (Figure 4C-D) and Fli-1 (not shown), indicating their EC identity. The hMAPC-ECs contributed to $2.3 \% \pm 0.7 \%$ of the vessels in the Matrigel plugs with standard media and $3.1 \% \pm 1.3 \%$ in arterial media, indicating that most cells of blood vessels in the Matrigel plugs were host derived. Dose-response studies revealed that engraftment strongly correlated with cell dose and cell dose with vascularity (Figure S7; Table S5).

Following transplantation with all cell doses $\left(0.5 \times 10^{6}\right.$ to $2.5 \times 10^{6}$ cells), several hMAPC-ECs generated in the presence of the arterial cytokine combination-while arterial marker expression was only detected with the highest cell dose with VEGF $_{165}$ alone (Figure S8) — expressed both human-specific lectin UEA and human-specific arterial markers Hey-2 and EphrinB1, as shown by immunohistochemistry (Figure 4E-F) and double immunofluorescence confocal microscopy (Figure 4G-H), demonstrating differentiation of hMAPCs in vivo to arterial endothelium. Importantly, these arterial hMAPC-ECs contributed to vessels functionally connected to the host vasculature as demonstrated by the presence of erythrocytes in their lumen (Figure 4F). Also, in some animals, we injected TRITC-labeled UEA lectin (that specifically binds to human ECs) in the tail vein 30 minutes before killing. Colabeling of TRITC-UEA with CFSE (with which the hMAPCs were labeled) confirmed that the hMAPC-EC-containing vessels were connected to the host vasculature (Figure 4I). Although transplanted hAC133 ${ }^{+}$ cells gave rise to $\mathrm{CD} 31^{+} \mathrm{UEA}$ lectin-positive ECs, the latter did not express arterial markers, nor were they associated with larger vessels (Figure S9). Thus, as in vitro, unlike $\mathrm{hAC} 133^{+}$cells, hMAPCs - and more so with the arterial cytokine mix — could be specified to functional arterial ECs in vivo.

In addition to its arterial differentiation effect on hMAPC-ECs, the arterial cytokine mix also induced the formation of arterial-like vessels in which both implanted and host cells participated. Indeed, coating with host $\alpha$-actin-positive SMCs of human EC-containing vessels was frequently observed in the Matrigel plugs containing the arterial cytokine combination, as shown by double confocal immunofluorescence (Figure 4J). Moreover, in addition to a significant increase in total vessel number (number of lectinpositive vessels: $124 \pm 16 / \mathrm{mm}^{2}$ in arterial media versus $74 \pm 10$ / $\mathrm{mm}^{2}$ in standard media; $\left.P<.05\right)$, the arterial mix also significantly increased the fraction of vessels coated with SMCs $(32 \% \pm 5 \%$ in arterial media versus $15 \% \pm 4 \%$ in standard media; $P<.05$; Figure 5A-C) as well as the diameter of these vessels $(20.1 \pm 4.2$ $\mu \mathrm{m}$ versus $14.7 \pm 3.7 \mu \mathrm{m} ; P=.01)$. Consistent with an effect of the cytokine mix on host cells, without addition of hMAPCs more $\alpha$-actin coated vessels were also seen in Matrigels containing arterial versus standard media. However, when hMAPCs were coimplanted, they had an additive effect on SMC coating (Figure 5C), in part by in situ differentiation to SMCs (not shown). Significantly more deposition of Sirius red-positive fibrillar collagen (Figure 5D-F) and orcein-positive elastin (not shown), both characteristics of arteries, could be detected surrounding the newly formed EC channels when hMAPCs and the arterial cytokine combination was used. Again, even in the absence of hMAPCs, there was more collagen deposition with the arterial mix than with standard media, although it was significantly higher when hMAPCs were coimplanted (Figure 5F). In addition to a direct contribution 


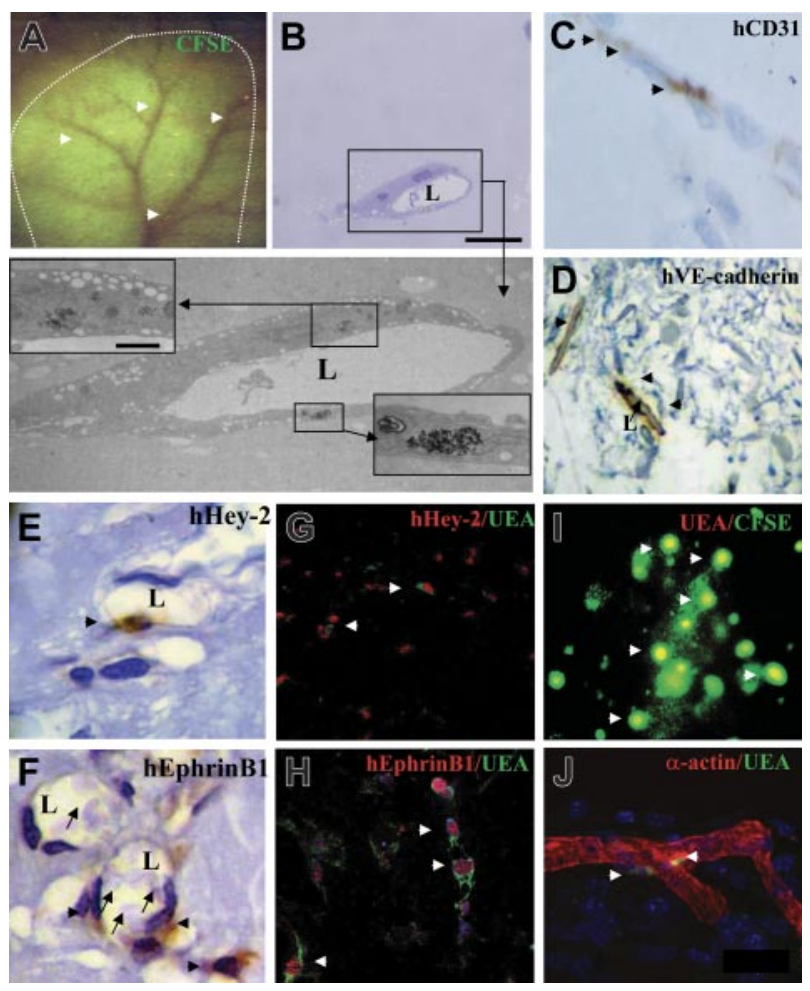

Figure 4. Shh and DIl-4 boost functional arterial hMAPC-EC differentiation in vivo. (A) Live in vivo imaging of a Matrigel plug containing VEGF 165 and hMAPCs labeled with CFSE 10 days after subcutaneous implantation. Note the localized CFSE-labeled area (outlined by a dashed white line) located in the Matrigel in the vicinity of a large vascular tree (arrowheads) from the overlying host skin. (B-J) Histologic analysis on cross-sections through Matrigel plugs containing hMAPCs and $\mathrm{VEFG}_{165}$ (B-D) or hMAPCs and VEGF ${ }_{165}+$ Shh + DIl-4 ("arterial cytokine mix" [E-J]). (B) Electron microscopy showing a capillary composed of a Resovist-labeled hMAPC-derived EC in Matrigel plugs. A semithin section (B, top panel), an ultrathin section ( $B$, bottom panel), and a detail of iron particles (insets in lower panel of $B$ ) are shown. (C-F) Immunohistochemical staining of $3 \mu \mathrm{m}$ paraffin cross-sections through Matrigel plugs for human-specific CD31 (C) and human-specific VE-cadherin (D) (both indicating their EC identity) and human-specific Hey-2 (E) and human-specific EphrinB1 ( $F$ ) (both indicating their arterial EC identity). Arrows indicate red blood cells in vessel lumen. (G-H) Double confocal immunofluorescence staining of $40 \mu \mathrm{m}$ cryopreserved cross-sections through Matrigel plugs with human endothelial-specific lectin UEA (green) and Hey-2 (red) (G) or UEA (green) and Ephrin B1 (red) (H). Topro (blue) was used for nuclear staining. (I) High-resolution live in vivo imaging of a Matrigel plug containing VEGF 165 and hMAPCs labeled with CFSE 10 days after subcutaneous implantation and 30 minutes after intravenous injection of UEA lectin. Note colocalization (yellow; indicated by arrowheads) of CFSE-labeled cells (green) and UEA lectin (red) area, indicating that the vessels containing CFSE-labeled cells were connected to the host vascular system. (J) Double confocal immunofluorescence staining of $40 \mu \mathrm{m}$ cryopreserved cross-sections through Matrigel plugs with human endothelial-specific lectin UEA (green) and $\alpha$-actin (red), showing hMAPCECs (arrowheads) coated by $\alpha$-actin-positive SMCs. Topro (blue) was used for nuclear staining. " $L$ " in panels $B$ and $D-F$ indicates the vessel lumen. Magnifications $\times 63(\mathrm{E}-\mathrm{F}), \times 40(\mathrm{C}-\mathrm{D}, \mathrm{J})$, and $\times 20(\mathrm{G}-\mathrm{I})$. Scale bars in panel B: $10 \mu \mathrm{m}$ (semithin); 2.5 $\mu \mathrm{m}$ (ultrathin); $1 \mu \mathrm{m}$ (upper inset); $0.5 \mu \mathrm{m}$ (lower inset).

to arterial growth, we hypothesized that the additive effect of hMAPCs on SMCs and extracellular matrix (ECM) coating was due to trophic effects by secretion of arteriogenic cytokines (similar to what has been described for other stem cells ${ }^{45}$ ). In support of such a hypothesis, an increase in the production of PDGF-BB and TGF- $\beta 1$, factors known to stimulate SMC proliferation and ECM production, was observed after in vitro culture of hMAPCs in the presence of the standard media and more so in the presence of the arterial cytokine combination (Figure 5G-H). Electron microscopic analysis further confirmed the differences in complexity and caliber between vessels formed in Matrigel plugs with standard versus arterial media (Figure 6). Together, these data indicate that the arterial cytokine combination induced the formation of vessels with arterial characteristics and that the presence of hMAPCs had an additive effect on this process.

\section{Discussion}

In the last decade, our knowledge about the molecular differences between arterial and venous ECs and the pathways underlying their specification during development has rapidly increased (reviewed by Lawson et al, ${ }^{20}$ Harvey and Oliver, ${ }^{46}$ Shawber and Kitajewski, ${ }^{47}$ and Iso et $\mathrm{al}^{48}$ ). That such specification is not only important during development but also in adult life is perhaps most clearly demonstrated by the occurrence of diseases restricted to arteries (eg, atherosclerosis) or veins (eg, varicose veins). Therefore, knowledge about the mechanisms that underlie EC specification may allow us to design more optimal therapeutic regimens for those diseases. Unfortunately, most of our understanding about AV specification is derived from animal studies. Therefore, the experiments presented here with human stem cells provide a valuable model for the elucidation of mechanisms involved in EC differentiation and AV specification in humans.

Developmental studies in zebrafish ${ }^{9,20}$ and Xenopus ${ }^{18}$ have demonstrated that AV specification occurs very early, at the level of the angioblast, the embryonic EC precursor. Currently, it is not known what initially determines arterial and venous angioblasts. Until recently, it was suggested that VEGF- the most widely explored angiogenic growth factor-equally affects proliferation and migration of all EC (precursor) types. However, evidence has now been presented that VEGF preferentially stimulates the growth of arterial ECs (and their precursors) during development (reviewed by Torres-Vazquez et $\mathrm{al}^{2}$ ) and adulthood. ${ }^{40}$ Several hypotheses have been put forward to explain VEGF's preference, but none of them has been unequivocally proven., ${ }^{2,20}$ Arterial angioblasts may respond differently because they are, as shown in Xenopus ${ }^{18}$ and zebrafish, ${ }^{9}$ the first ones to migrate and thus encounter the VEGF signal earlier. Alternatively, specific responses may be elicited by the need for a coreceptor for $\mathrm{VEGF}_{165}$ to engage the downstream Notch pathway. Recent evidence has shown that NP-1, which only binds the $\mathrm{VEGF}_{165}$ isoform, might be a candidate coreceptor. ${ }^{6,17}$ Although our in vitro system did not allow addressing the spatially different responses of arterial and venous angioblasts to VEGF, our findings support the notion that, like in zebrafish and mouse development, there are separate arterial and venous endothelial precursors in the adult human. Under conditions in which hMAPCs gave robust arterial EC differentiation, $\mathrm{hAC} 133^{+}$cells appeared to have lost that ability both in vitro and in vivo and therefore could be considered venous EPCs. In contrast, hMAPCs are less mature than EPCs ${ }^{32}$ and may constitute a cell population that precedes AV specification and can therefore differentiate to both arterial and venous ECs in the presence of $\mathrm{VEGF}_{165}$. Noteworthy in this context is the fact that $\mathrm{hAC} 133^{+}$cells gave rise to venous and $\mathrm{CD} 36^{+}$microvascular ECs, while hMAPCs differentiated mainly into $\mathrm{CD}^{-} 6^{-}$macrovascular ECs.

During zebrafish development, VEGF is part of an arterial EC inductive sequence involving Shh (acting upstream from VEGF) and Notch (acting downstream), ${ }^{20}$ a cascade that is at least in part conserved in mouse development (reviewed by Harvey and Oliver ${ }^{46}$ ). Using hMAPCs, we demonstrate both by positive and negative manipulation that the Shh and Notch elements of this cascade are also active during arterial EC specification from adult human stem cells. Although we show that $\mathrm{VEGF}_{165}$, Shh, and Dll-4 

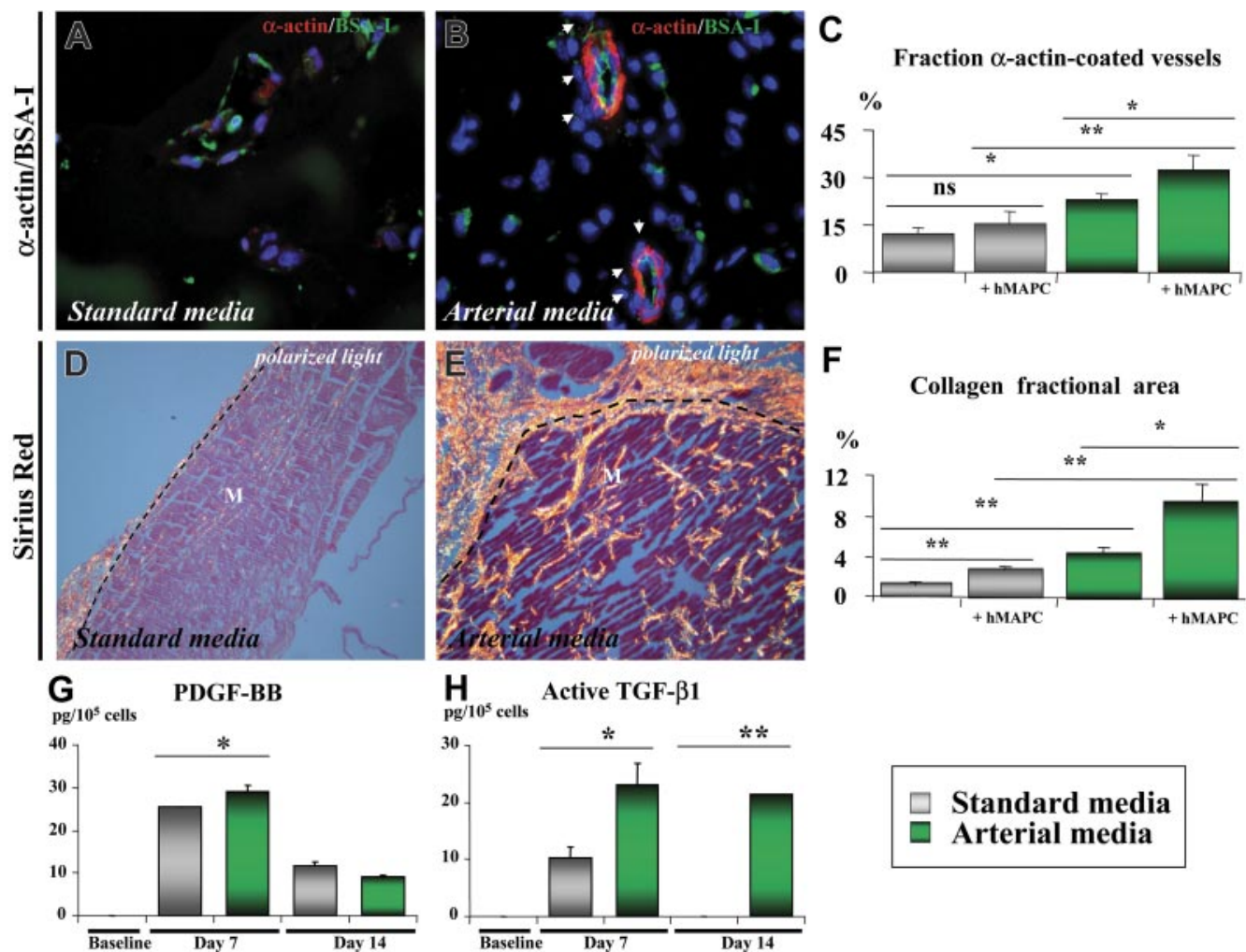

5. Shh and DIl-4 together with hMAPCs additively increase formation of arterial-like vascular structures in vivo. (A-F) Histologic analysis on cross-sections through Matrigel plugs containing hMAPCs and VEFG ${ }_{165}(A, D)$ or hMAPCs and VEGF ${ }_{165}+$ Shh + Dll-4 (B,E). (A-B) Double immunofluorescent staining of $3 \mu m$ paraffin cross-sections through Matrigel plugs stained with SMC $\alpha$-actin (red) and BS-I lectin (staining ECs in green) showing more SMC-coated (indicated by arrowheads) vessels when the arterial media were used (B) in comparison with standard media (A). (C) Diagram comparing the fraction of SMC-coated vessels (expressed as percentage \pm SEM versus the total number of vessels) for the conditions outlined in the box; ${ }^{*} P<.05 ;{ }^{*} P<.01$. Note the additive effect of hMAPCs. (D-E) Sirius red staining (visualized by polarized light microscopy) indicating abundant and thick (orange-red birefringent) fibrillar collagen around vessels in Matrigels containing hMAPCs combined with the arterial mix (E) as compared with the less abundant and thinner collagen in Matrigels containing hMAPCs combined with VEGF 165 alone (D); dashed lines indicate the edge of the Matrigel (M). (F) Diagram comparing the collagen fractional area (expressed as percentage \pm SEM versus the total area) for the conditions outlined in the legend; ${ }^{*}<.05$; ${ }^{* *} P<.01$. Note the additive effect of hMAPCs. (G,H) ELISA for PDGF-BB (G) and active TGF- $\beta 1$ (H) on cell supernatants of undifferentiated hMAPCs ("baseline") or differentiated for 7 or 14 days to ECs either in standard media (gray bars) or arterial media (green bars). While PDGF-BB production was only slightly and temporarily higher, active TGF- $\beta 1$ production was significantly higher in arterial media versus standard media. ${ }^{\star} P<.05 ;{ }^{\star \star} P<.01$. Data are expressed as picogram per $10^{5}$ cells and represent the mean ( \pm SEM) of 3 experiments performed in triplicate.
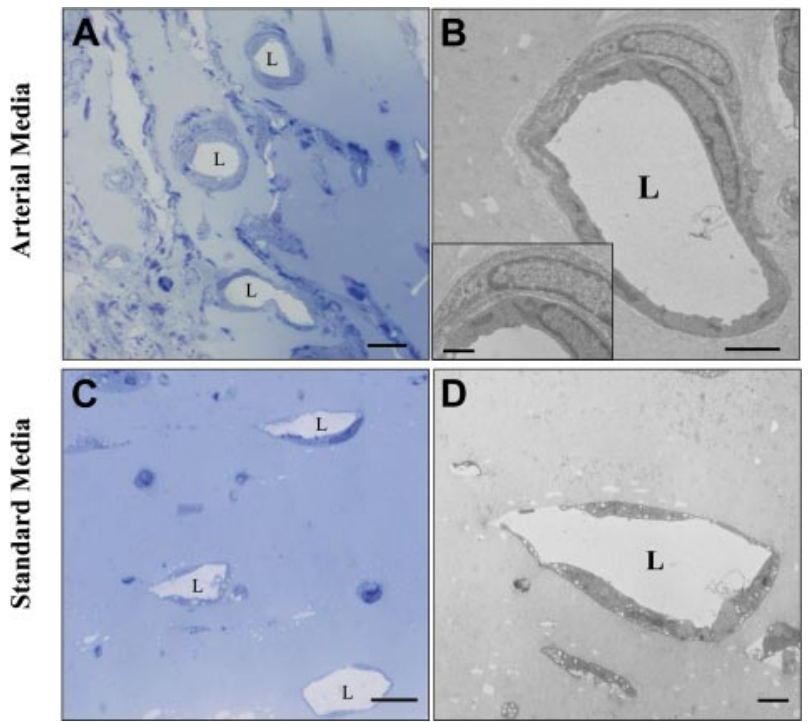

Figure 6. Ultrastructural comparison between the vessel make-up in Matrigel plugs injected with hMAPCs in arterial or standard media. Ultrastructural analysis of Matrigel plugs injected subcutaneously with hMAPCs combined with arterial (A-B) or standard media (C-D). Semithin sections of a Matrigel plug (A,C) and an ultrathin section of an artery-like tube (B) with a detail showing an SMC around an EC (inset) and a veinlike tube (D). "L" indicates the vessel lumen. Scale bars: $10 \mu \mathrm{m}$ $(A, C) ; 2.5 \mu \mathrm{m}(B) ; 2 \mu \mathrm{m}(\mathrm{D}) ; 1 \mu \mathrm{m}$ (B, inset). may have an additive effect on arterial EC differentiation, additional mechanistic studies will help to determine whether they work in a similar cascade. The involvement of those pathways was further substantiated by the differential expression of many of the pathway members in hMAPCs and hAC133+ cells. Increased expression of the patched receptors in hMAPCs may be the result of an autocrine positive feedback loop ${ }^{49,50}$ driven by hMAPCderived Shh. Intriguingly, while Notch-1 was exclusively expressed in hMAPCs, Notch-4 was significantly underexpressed in hMAPCs in comparison with hAC $133^{+}$cells. Recent studies have, however, demonstrated the redundancy between Notch-1 and -4 , supporting the notion that Notch-1 may be sufficient to induce arterial EC differentiation in hMAPCs. ${ }^{51}$ The fact that not all arterial markers were elevated in hMAPCs under the influence of VEGF $_{165}$ (combined or not with Notch and patched ligands) and that arterial differentiation was not completely abrogated by Notch and/or Shh blocking may reflect the existence of additional VEGF/Notch/patched-independent pathways in arterial differentiation. We did, for instance, not fully explore the potential involvement of TGF- $\beta$, COUP-TFII, adrenomedullin, or angiopoietins, known to play a role in AV fate decisions. ${ }^{7,14,22,40}$

During development and in primary ECs, ${ }^{52}$ Notch activation has been associated with endothelial-to-mesenchymal transformation. Despite the ability of hMAPCs to robustly differentiate into SMCs 
under other conditions (Figure S1; Document S1), the conditions used for EC differentiation induced SMC differentiation of hMAPCs in vitro and in vivo to a low degree (not shown). This lack of significant SMC (trans)differentiation, however, allowed us to conclude that changes in expression of certain Notch components (like Jagged-1 and Ephrin B2, which have been shown to be expressed also in arterial $\mathrm{SMCs}^{48,53}$ ) were $\mathrm{EC}$ specific in our system. However, we cannot exclude that activation of Notch in fully EC-differentiated MAPCs may induce such transformation. Dll-4-induced Notch activation in ECs was recently shown to down-regulate EC proliferation, maybe due to an attenuated responsiveness to VEGF. ${ }^{54}$ However, despite this inhibitory effect on EC proliferation, Notch activation was still compatible with up-regulation of arterial EC markers, such as Hey-2, similar to what we and others documented in in vitro studies. ${ }^{55,56}$ Shh has also been shown to support neuronal differentiation, ${ }^{57}$ yet we did not observe the formation of neurons in our system despite the intrinsic ability of hMAPCs for neuronal differentiation, the latter of which requires a different cytokine cocktail (Figure S1; Document S1).

In agreement with the in vitro data, hMAPCs but not hAC133+ cells were capable of arterial EC differentiation in vivo. Indeed, the combination of VEGF $_{165}$, Shh, and Dll-4 boosted arterial EC differentiation from coimplanted hMAPCs. In addition, this arterial "cocktail" induced a different vascular pattern than $\mathrm{VEGF}_{165}$ alone (ie, vessels were larger in diameter, more frequently coated with host SMCs, and contained elastin and more fibrillar collagenaltogether features consistent with arterial vessels). Other studies have shown that in the setting of ischemia, vessels formed in the presence of Shh had similar characteristics as the ones described here (ie, larger-diameter vessels and more often coated with SMCs). ${ }^{50,58}$ In our study, injection of the arterial cocktail without hMAPCs also induced effects on the endogenous mouse vascular cells but, importantly, the effects were more pronounced in the presence of hMAPCs. We hypothesize that, in addition to their direct contribution to arterial endothelium, hMAPCs (similar to other stem cells ${ }^{45}$ ), and more so when cultured in arterial media, had trophic effects on endogenous cells through secretion of PDGF-BB and TGF- $\beta 1$. Interestingly, as previously shown in tumors, Shh in the arterial mix or produced by hMAPCs could potentially enhance PDGF receptor expression on the host vasculature and thereby enhance its response to the hMAPC-derived PDGF-BB signal. ${ }^{59}$

Together, our data show that coaxing human stem cells in vitro and in vivo (along with endogenous vascular cells) specifically into an arterial phenotype is feasible, thereby providing a model to study AV specification in humans. Moreover, our findings may also be of importance for improvement and optimization of strategies for vascular regeneration in ischemic patients and for the design of EC-coated artificial arterial grafts.

\section{Acknowledgments}

This work as supported in part by grants from the Health Department of the Government of Navarra (4/2004), Spanish Ministerio de Ciencia y Tecnología (SAF 2002-04574-C02), Ministerio de Sanidad PI050168, FEDER (INTERREG IIIA) the UTE project CIMA, the American Heart Association (A.L., B.P.), Excellentie financiering KULeuven (EF/05/013) (A.L.), and the Belgian American Educational Foundation (BAEF) (A.L.).

\section{Authorship}

Contribution: X.L.A. and C.C. performed and designed research, collected data, and analyzed data; A.L., C.M.V., and F.P. designed research, analyzed data, and wrote the manuscript; C.M., G.A., M.A.B., B.P., M.U., M.A., A.E., M.S., E.J.A., and J.M. performed research and collected data; and J.M.G.-V. contributed analytical tools and collected and interpreted data.

Conflict-of-interest disclosure: The authors declare no competing financial interests.

X.L.A., A.L., and C.C. contributed equally to this study.

Correspondence: Felipe Prósper, Hematology and Cell Therapy Area, Clínica Universitaria, University of Navarra, Av Pio XII 36, Pamplona 31009, Spain; e-mail: fprosper@unav.es.

\section{References}

1. Carmeliet P. Manipulating angiogenesis in medicine. J Intern Med. 2004;255:538-561.

2. Torres-Vazquez J, Kamei M, Weinstein BM. Molecular distinction between arteries and veins. Cell Tissue Res. 2003;314:43-59.

3. Jain RK. Molecular regulation of vessel maturation. Nat Med. 2003;9:685-693.

4. Bagley RG, Walter-Yohrling J, Cao X, et al. Endothelial precursor cells as a model of tumor endothelium: characterization and comparison with mature endothelial cells. Cancer Res. 2003;63: 5866-5873.

5. Chi JT, Chang HY, Haraldsen G, et al. Endothelial cell diversity revealed by global expression profiling. Proc Natl Acad Sci U S A. 2003;100:1062310628.

6. You LR, Lin FJ, Lee CT, DeMayo FJ, Tsai MJ, Tsai SY. Suppression of Notch signalling by the COUP-TFII transcription factor regulates vein identity. Nature. 2005;435:98-104.

7. Villa N, Walker L, Lindsell CE, Gasson J, IruelaArispe ML, Weinmaster G. Vascular expression of Notch pathway receptors and ligands is restricted to arterial vessels. Mech Dev. 2001;108:161-164.

8. Shutter JR, Scully S, Fan W, et al. DII4, a novel Notch ligand expressed in arterial endothelium. Genes Dev. 2000;14:1313-1318.

9. Zhong TP, Childs S, Leu JP, Fishman MC. Grid- lock signalling pathway fashions the first embryonic artery. Nature. 2001;414:216-220.

10. Zhong TP, Rosenberg M, Mohideen MA, Weinstein B, Fishman MC. gridlock, an HLH gene required for assembly of the aorta in zebrafish. Science. 2000;287:1820-1824.

11. le Noble F, Moyon D, Pardanaud L, et al. Flow regulates arterial-venous differentiation in the chick embryo yolk sac. Development. 2004;131: 361-375.

12. Othman-Hassan K, Patel K, Papoutsi M, Rodriguez-Niedenfuhr M, Christ B, Wilting J. Arterial identity of endothelial cells is controlled by local cues. Dev Biol. 2001;237:398-409.

13. Mukouyama YS, Shin D, Britsch S, Taniguchi M, Anderson DJ. Sensory nerves determine the pattern of arterial differentiation and blood vessel branching in the skin. Cell. 2002;109:693-705.

14. Waite KA, Eng C. From developmental disorder to heritable cancer: it's all in the BMP/TGF-beta family. Nat Rev Genet. 2003;4:763-773.

15. Sorensen LK, Brooke BS, Li DY, Urness LD. Loss of distinct arterial and venous boundaries in mice lacking endoglin, a vascular-specific TGFbeta coreceptor. Dev Biol. 2003;261:235-250.

16. Stalmans I, Ng YS, Rohan R, et al. Arteriolar and venular patterning in retinas of mice selectively expressing VEGF isoforms. J Clin Invest. 2002; 109:327-336.

17. Mukouyama YS, Gerber HP, Ferrara N, Gu C, Anderson DJ. Peripheral nerve-derived VEGF promotes arterial differentiation via neuropilin 1-mediated positive feedback. Development. 2005;132:941-952.

18. Cleaver O, Krieg PA. VEGF mediates angioblast migration during development of the dorsal aorta in Xenopus. Development. 1998;125:3905-3914.

19. Moyon D, Pardanaud L, Yuan L, Breant C, Eichmann A. Selective expression of angiopoietin 1 and 2 in mesenchymal cells surrounding veins and arteries of the avian embryo. Mech Dev. 2001;106:133-136.

20. Lawson ND, Vogel AM, Weinstein BM. sonic hedgehog and vascular endothelial growth factor act upstream of the Notch pathway during arterial endothelial differentiation. Dev Cell. 2002;3:127136.

21. Liu ZJ, Shirakawa T, Li Y, et al. Regulation of Notch 1 and DII4 by vascular endothelial growth factor in arterial endothelial cells: implications for modulating arteriogenesis and angiogenesis. Mol Cell Biol. 2003;23:14-25.

22. Yurugi-Kobayashi $\mathrm{T}$, Itoh $\mathrm{H}$, Schroeder $\mathrm{T}$, et al Adrenomedullin/cyclic AMP pathway induces 
Notch activation and differentiation of arterial endothelial cells from vascular progenitors. Arterioscler Thromb Vasc Biol. 2006;26:1977-1984.

23. Masood R, Xia G, Smith DL, et al. Ephrin B2 expression in Kaposi sarcoma is induced by human herpesvirus type 8: phenotype switch from venous to arterial endothelium. Blood. 2005;105: 1310-1318.

24. Shawber CJ, Das I, Francisco E, Kitajewski J. Notch signaling in primary endothelial cells. Ann N Y Acad Sci. 2003:995:162-170.

25. Asahara T, Murohara T, Sullivan A, et al. Isolation of putative progenitor endothelial cells for angiogenesis. Science. 1997;275:964-967.

26. Gehling UM, Ergun S, Schumacher U, et al. In vitro differentiation of endothelial cells from AC133-positive progenitor cells. Blood. 2000;95: 3106-3112.

27. Salven P, Mustjoki S, Alitalo R, Alitalo K, Rafii S. VEGFR-3 and CD133 identify a population of CD34+ lymphatic/vascular endothelial precursor cells. Blood. 2003;101:168-172.

28. Pelosi E, Valtieri M, Coppola S, et al. Identification of the hemangioblast in postnatal life. Blood. 2002;100:3203-3208.

29. Jiang Y, Henderson D, Blackstad M, Chen A, Miller RF, Verfaillie CM. Neuroectodermal differentiation from mouse multipotent adult progenitor cells. Proc Natl Acad Sci U S A. 2003;100(suppl 1):11854-11860

30. Jiang $Y$, Jahagirdar BN, Reinhardt RL, et al. Pluripotency of mesenchymal stem cells derived from adult marrow. Nature. 2002;418:41-49.

31. Schwartz RE, Reyes M, Koodie L, et al. Multipotent adult progenitor cells from bone marrow differentiate into functional hepatocyte-like cells. J Clin Invest. 2002;109:1291-1302.

32. Reyes M, Dudek A, Jahagirdar B, Koodie L, Marker PH, Verfaillie CM. Origin of endothelia progenitors in human postnatal bone marrow. J Clin Invest. 2002;109:337-346.

33. Reyes M, Lund T, Lenvik T, Aguiar D, Koodie L, Verfaillie CM. Purification and ex vivo expansion of postnatal human marrow mesodermal progenitor cells. Blood. 2001;98:2615-2625.

34. de Wynter EA, Buck D, Hart C, et al. CD34+AC133+ cells isolated from cord blood are highly enriched in long-term culture-initiating cells, NOD/SCID-repopulating cells and dendritic cell progenitors. Stem Cells. 1998;16:387-396.

35. Watkins DN, Berman DM, Burkholder SG, Wang $B$, Beachy PA, Baylin SB. Hedgehog signalling within airway epithelial progenitors and in smallcell lung cancer. Nature. 2003;422:313-317.
36. Dahlqvist C, Blokzijl A, Chapman G, et al. Functional Notch signaling is required for BMP4-induced inhibition of myogenic differentiation. Development. 2003;130:6089-6099.

37. Luttun A, Lupu F, Storkebaum E, et al. Lack of plasminogen activator inhibitor-1 promotes growth and abnormal matrix remodeling of advanced atherosclerotic plaques in apolipoprotein E-deficient mice. Arterioscler Thromb Vasc Biol. 2002;22:499-505.

38. Salvato G. Quantitative and morphological analy sis of the vascular bed in bronchial biopsy specimens from asthmatic and non-asthmatic subjects. Thorax. 2001;56:902-906.

39. Arbab AS, Bashaw LA, Miller BR, Jordan EK Bulte JW, Frank JA. Intracytoplasmic tagging of cells with ferumoxides and transfection agent for cellular magnetic resonance imaging after cell transplantation: methods and techniques. Transplantation. 2003;76:1123-1130.

40. Visconti RP, Richardson CD, Sato TN. Orchestration of angiogenesis and arteriovenous contribution by angiopoietins and vascular endothelial growth factor (VEGF). Proc Natl Acad Sci U S A. 2002;99:8219-8224.

41. Petzelbauer P, Bender JR, Wilson J, Pober JS. Heterogeneity of dermal microvascular endothelial cell antigen expression and cytokine responsiveness in situ and in cell culture. J Immunol. 1993;151:5062-5072.

42. Ades EW, Candal FJ, Swerlick RA, et al. HMEC-1: establishment of an immortalized human microvascular endothelial cell line. J Invest Dermatol. 1992;99:683-690.

43. Swerlick RA, Lee KH, Wick TM, Lawley TJ. Human dermal microvascular endothelial but not human umbilical vein endothelial cells express CD36 in vivo and in vitro. J Immunol. 1992;148: 78-83.

44. Arbab AS, Bashaw LA, Miller BR, et al. Characterization of biophysical and metabolic properties of cells labeled with superparamagnetic iron oxide nanoparticles and transfection agent for cellular MR imaging. Radiology. 2003;229:838-846.

45. Kinnaird T, Stabile E, Burnett MS, et al. Marrowderived stromal cells express genes encoding a broad spectrum of arteriogenic cytokines and promote in vitro and in vivo arteriogenesis through paracrine mechanisms. Circ Res. 2004;94:678685

46. Harvey NL, Oliver G. Choose your fate: artery, vein or lymphatic vessel? Curr Opin Genet Dev. 2004;14:499-505.

47. Shawber CJ, Kitajewski J. Notch function in the vasculature: insights from zebrafish, mouse and man. Bioessays. 2004;26:225-234.

48. Iso T, Hamamori Y, Kedes L. Notch signaling in vascular development. Arterioscler Thromb Vasc Biol. 2003;23:543-553.

49. Marigo V, Johnson RL, Vortkamp A, Tabin CJ. Sonic hedgehog differentially regulates expression of GLI and GLI3 during limb development. Dev Biol. 1996;180:273-283.

50. Pola R, Ling LE, Silver M, et al. The morphogen Sonic hedgehog is an indirect angiogenic agent upregulating two families of angiogenic growth factors. Nat Med. 2001;7:706-711.

51. Carlson TR, Yan Y, Wu X, et al. Endothelial expression of constitutively active Notch4 elicits reversible arteriovenous malformations in adult mice. Proc Natl Acad Sci U S A. 2005;102:98849889.

52. Noseda M, McLean G, Niessen K, et al. Notch activation results in phenotypic and functional changes consistent with endothelial-to-mesenchymal transformation. Circ Res. 2004;94:910917.

53. Gale NW, Baluk P, Pan L, et al. Ephrin-B2 selectively marks arterial vessels and neovascularization sites in the adult, with expression in both endothelial and smooth-muscle cells. Dev Biol. 2001;230:151-160.

54. Williams CK, Li JL, Murga M, Harris AL, Tosato G. Upregulation of the Notch ligand Delta-like 4 inhibits VEGF-induced endothelial cell function. Blood. 2006;107:931-939

55. Lawson ND, Scheer N, Pham VN, et al. Notch signaling is required for arterial-venous differentiation during embryonic vascular development. Development. 2001;128:3675-3683.

56. Fischer A, Schumacher N, Maier M, Sendtner M Gessler M. The Notch target genes Hey1 and Hey2 are required for embryonic vascular development. Genes Dev. 2004;18:901-911.

57. Benedito R, Duarte A. Expression of DIl4 during mouse embryogenesis suggests multiple developmental roles. Gene Expr Patterns. 2005;5:750755

58. Kusano KF, Allendoerfer KL, Munger W, et al. Sonic hedgehog induces arteriogenesis in diabetic vasa nervorum and restores function in diabetic neuropathy. Arterioscler Thromb Vasc Biol. 2004;24:2102-2107.

59. Ruiz i Altaba A, Sanchez P, Dahmane N. Gli and hedgehog in cancer: tumours, embryos and stem cells. Nat Rev Cancer. 2002;2:361-372. 


\section{Differentiation of hMAPCs}

Smooth muscle differentiation. Human MAPCs were plated at $1 \times 10^{3} / \mathrm{cm}^{2}$ in growth media: $58 \%$ lowglucose DMEM (Gibco BRL), 40\% MCDB-201 (Sigma), 2\% FCS (Biochrom), ITS+1 (Sigma), 10-8 M dexamethasone (Sigma), 10 $10^{-4} \mathrm{M}$ ascorbic acid 2-phosphate (Sigma), 100 units of penicillin and 1000 units of streptomycin (Gibco BRL), and $10 \mathrm{ng} / \mathrm{mL}$ each of PDGF-BB and EGF during 24 hours, and then media were exchanged with the same basal media without FCS and EGF but now with $10 \mathrm{ng} / \mathrm{mL}$ TGF- $\beta 1$. Media were changed every 4 to 5 days.

Hepatocyte differentiation. Human MAPCs were plated at $30 \times 10^{3}$ to $40 \times 10^{3} / \mathrm{cm}^{2}$ on $1 \%$ Matrigel-coated plates in differentiation media with $50 \mathrm{ng} / \mathrm{mL}$ FGF-4 and $50 \mathrm{ng} / \mathrm{mL}$ HGF. Media were changed every 4 to 5 days.

Neuronal differentiation. Human MAPCs were plated at $10 \times 10^{3}$ to $15 \times 10^{3} / \mathrm{cm}^{2}$ in growth media: $58 \%$ low-glucose DMEM (Gibco BRL), 40\% MCDB-201 (Sigma), 2\% FCS (Biochrom), ITS+1 (Sigma), 10-8 M dexamethasone (Sigma), $10^{-4} \mathrm{M}$ ascorbic acid 2-phosphate (Sigma), 100 units of penicillin and 1000 units of streptomycin (Gibco BRL), and $10 \mathrm{ng} / \mathrm{mL}$ each of PDGF-BB and EGF during 24 hours, and then media were exchanged with the same basal media without FCS, EGF, and PDGF-BB but now with $100 \mathrm{ng} / \mathrm{mL}$ bFGF. Media were changed every 4 to 5 days. After 1 week, 100 ng/mL Shh and 50 ng/mL FGF-8 were added to the differentiation media, and $50 \mathrm{ng} / \mathrm{mL}$ BDNF was added during the third week.

\section{RNA isolation and real-time and quantitative RT-PCR}

Total RNA was obtained using the RNeasy Mini extraction kit (Qiagen) according to the manufacturer's instructions. The first-strand cDNA was synthesized using random primers and MMLV retrotranscriptase. For PCR amplification, Taq (Roche, Mannheim, Germany) was used in $25 \mu \mathrm{L}$ reaction mixture, including $0.2 \mathrm{mM}$ dNTPs (Invitrogen, Paisley, United Kingdom) and $0.8 \mu \mathrm{M}$ of each primer (Sigma). PCR program parameters were 10 minutes of initial denaturation at $94^{\circ} \mathrm{C}$; later, 30 to 35 cycles of $94^{\circ} \mathrm{C}$ for 1 minute, annealing for 1 minute, and elongation at $72^{\circ} \mathrm{C}$ for 1 minute; followed by 7 minutes of extension at $72^{\circ} \mathrm{C}$. Subsequently, PCR products were visualized in 1.5\% ethidium bromide-stained agarose gels. For quantitative RT-PCR Syber Green or Taq Man methods were used as described. ${ }^{1}$ GAPDH was used as housekeeping control. Results are presented as fold increase in comparison with the expression of the gene in undifferentiated cells or as percentage of positive control (cord blood-derived venous and arterial ECs). Primers used for both RT-PCR and real-time PCR are shown in Table S3.

\section{References}

1. Hong YK, Foreman K, Shin JW, et al. Lymphatic reprogramming of blood vascular endothelium by Kaposi sarcoma-associated herpesvirus. Nat Genet. 2004;36:683-685.

2. Jiang Y, Henderson D, Blackstad M, Chen A, Miller RF, Verfaillie CM. Neuroectodermal differentiation from mouse multipotent adult progenitor cells. Proc Natl Acad Sci U S A. 2003;100(suppl 1):11854-11860. 
Table S1a: FACS phenotyping

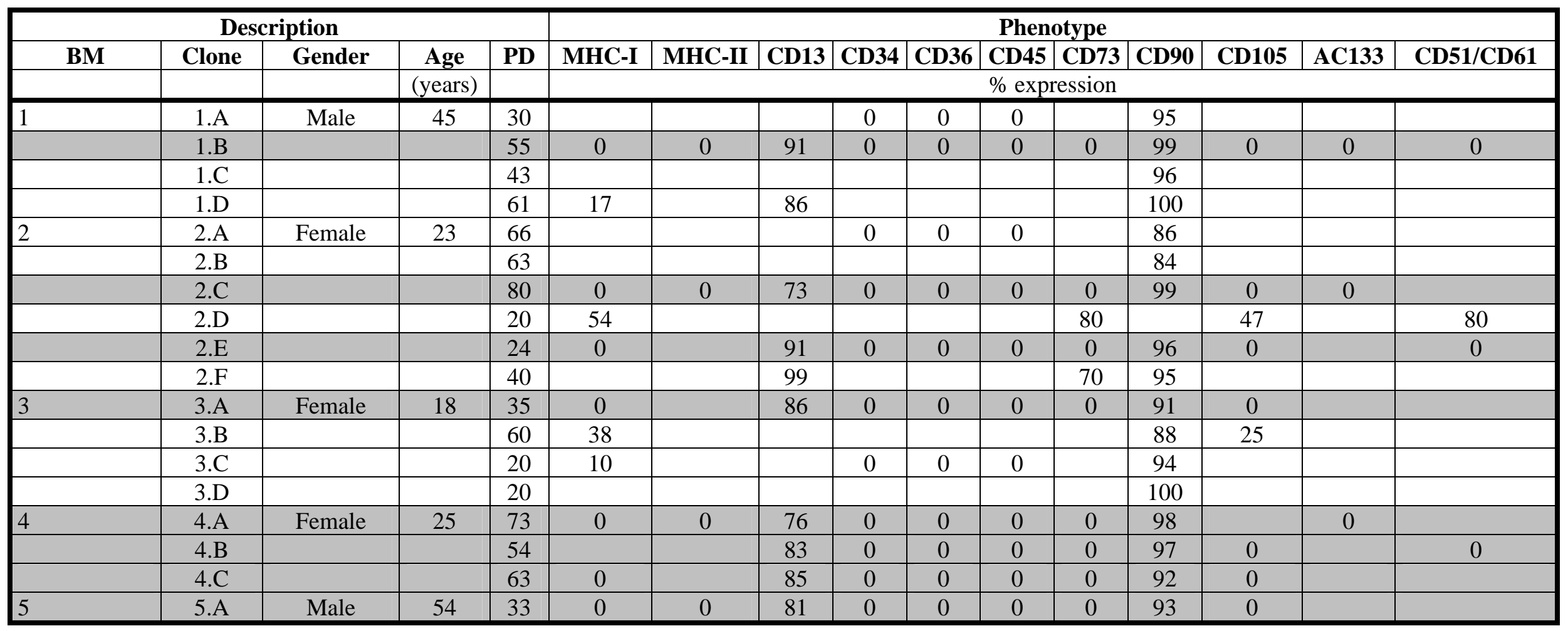




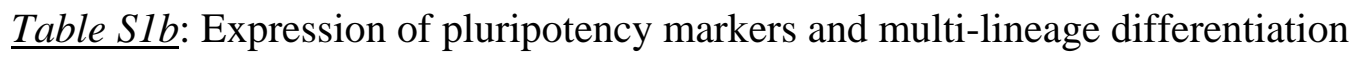

\begin{tabular}{|c|c|c|c|c|c|c|c|c|c|c|c|c|c|c|c|c|c|}
\hline \multicolumn{2}{|c|}{ Description } & \multicolumn{8}{|c|}{ Phenotype } & \multicolumn{8}{|c|}{ Differentiations } \\
\hline & & \multicolumn{2}{|c|}{ Oct3/4 } & \multicolumn{2}{|c|}{ Nanog } & \multicolumn{2}{|c|}{ SSEA-4 } & \multicolumn{2}{|c|}{ SSEA-1 } & \multicolumn{2}{|c|}{ Endothelium } & \multicolumn{2}{|c|}{ Smooth muscle } & \multicolumn{2}{|c|}{ Hepatocyte } & \multicolumn{2}{|c|}{ Neuronal } \\
\hline BM & Clone & PCR & IF & PCR & IF & PCR & IF & PCR & IF & PCR & IF & PCR & IF & PCR & IF & PCR & IF \\
\hline \multirow[t]{4}{*}{1} & 1.A & & & & & & & & & Positive & Positive & & & & & & \\
\hline & $1 . \mathrm{B}$ & Positive & Positive & Positive & Positive & & Positive & & & Positive & Positive & Positive & Positive & Positive & Positive & Positive & Positive \\
\hline & 1.C & & & & & & & & & Positive & & Positive & & & & & \\
\hline & 1.D & Negative & & Positive & & & & & & & & & & Negative & & Negative & \\
\hline \multirow[t]{6}{*}{2} & 2.A & & & & & & & & & Positive & Positive & & & & & Negative & \\
\hline & 2.B & & & & & & & & & & & & & & & & \\
\hline & 2.C & Positive & & Positive & & & & & & Positive & Positive & & & Positive & & Positive & \\
\hline & 2.D & & & & & & & & & & & & & Negative & & Negative & \\
\hline & 2.E & Positive & Positive & Positive & & & & & & Positive & Positive & Positive & Positive & Positive & Positive & Positive & Positive \\
\hline & $2 . \mathrm{F}$ & & & & & & & & & & & & & Positive & Negative & Negative & \\
\hline \multirow[t]{4}{*}{3} & 3.A & Positive & & Positive & Positive & & Positive & & Negative & Positive & Positive & & & Positive & Positive & Positive & Positive \\
\hline & 3.B & Positive & Negative & Positive & & & & & & Positive & & Positive & & & & & \\
\hline & 3.C & & & & & & & & & Positive & Positive & & & Positive & Negative & & \\
\hline & 3.D & & & & & & & & & & & & & & & & \\
\hline \multirow[t]{3}{*}{4} & 4.A & Positive & Positive & Positive & & & & & & Positive & Positive & Positive & Positive & Positive & Positive & Positive & Positive \\
\hline & 4.B & Positive & & Positive & & & & & & Positive & Positive & & & Positive & & Positive & \\
\hline & 4.C & Positive & Positive & Positive & Positive & & Positive & & Negative & Positive & Positive & & & Positive & & Positive & \\
\hline 5 & 5.A & Positive & & Positive & & & & & & Positive & Positive & & & Positive & Positive & Positive & Positive \\
\hline
\end{tabular}

Shaded boxes represent the 8 clones used in the current study. Each clone was subjected to FACS analysis, real time PCR for expression of pluripotency markers and in vitro differentiation as described in the Materials and Methods section. Tri-lineage differentiation was assessed by real time PCR and immunofluorescence for specific markers for endothelium, smooth muscle, hepatocyte and neural as described in the Materials and Methods section and Supplemental Fig. 1 and 2. An empty box means that the analysis was not done. BM: bone marrow; PD: population doubling; IF: immunofluorescence 


\begin{tabular}{|c|c|c|}
\hline Antibody & Provided by & Application \\
\hline CD90-APC & BD & FACS \\
\hline CD13-PE & $\mathrm{BD}$ & FACS \\
\hline MHC-I-PE & $\mathrm{BD}$ & FACS \\
\hline MHC-II-PE & $\mathrm{BD}$ & FACS \\
\hline$\alpha v \beta 3-P E$ & $\mathrm{BD}$ & FACS \\
\hline CD73-PE & $\mathrm{BD}$ & FACS \\
\hline AC133-PE /-APC & Miltenyi-Biotec & FACS \\
\hline CD105-PE & Ancell & FACS \\
\hline CD36-FITC & BD & FACS \\
\hline CD45-PerCP & $\mathrm{BD}$ & FACS \\
\hline CD34-APC & $\mathrm{BD}$ & FACS \\
\hline CD31-PE & $\mathrm{BD}$ & FACS \\
\hline CD16+CD56-PE & $\mathrm{BD}$ & FACS \\
\hline CD3-FITC & $\mathrm{BD}$ & FACS \\
\hline CD19-APC & $\mathrm{BD}$ & FACS \\
\hline CD11b-PE & $\mathrm{BD}$ & FACS \\
\hline CD11c-APC & $\mathrm{BD}$ & FACS \\
\hline EphrinB1 (human-specific) & Zymed & IHQ- Immunofluorescence \\
\hline Hey-2 (human-specific) & Chemicon & IHQ- Immunofluorescence \\
\hline EphB4 & Santa Cruz & Immunofluorescence \\
\hline CD31 & DAKO & IHQ- Immunofluorescence \\
\hline VE-cadherin & Chemicon & IHQ \\
\hline UEA lectin (human-specific) & Sigma & IHQ- Immunofluorescence \\
\hline$\alpha$-actin & DAKO and Sigma & IHQ- Immunofluorescence \\
\hline BS-I lectin (mouse-specific) & Sigma & Immunofluorescence \\
\hline Fli-1 & $\mathrm{BD}$ & IHQ \\
\hline SSEA-1 & Chemicon & Immunofluorescence \\
\hline SSEA-4 & Chemicon & Immunofluorescence \\
\hline Oct3/4 & Santa Cruz & Immunofluorescence \\
\hline Nanog & R\&DSystems & Immunofluorescence \\
\hline vWF & Santa Cruz & Immunofluorescence \\
\hline Tie-1 & Santa Cruz & Immunofluorescence \\
\hline Tie-2 & Santa Cruz & Immunofluorescence \\
\hline KDR & Santa Cruz & Immunofluorescence \\
\hline Flt-1 & Santa Cruz & Immunofluorescence \\
\hline Albumin & Dako & Immunofluorescence \\
\hline$\beta 3$-tubulin & Chemicon & Immunofluorescence \\
\hline Vimentin (human-specific) & Dako & Immunofluorescence \\
\hline
\end{tabular}




\begin{tabular}{|c|c|c|c|}
\hline General EC & Sense & Antisense & Probe \\
\hline CD31 & ACTGCACAGCCTTCAACAGA & TTTCTTCCATGGGGCAAG & SYBER GREEN \\
\hline CD34 & TCCAGAAACGGCCATTCAG & CCCCACCTAGCCGAGTCA & SYBER GREEN \\
\hline KDR & TCCTGTATGGAGGAGGAGGA & CGGCTCTTTCGCTTACTGTT & SYBER GREEN \\
\hline Flt-1 & GGACTGACAGCAAACCCAAG & CAGCCCCGACTCCTTACTTT & SYBER GREEN \\
\hline Tie-2 & TGCCCAGATATTGGTGTCCT & CTCATAAAGCGTGGTATTCACGTA & SYBER GREEN \\
\hline vWF & GTCGAGCTGCACAGTGACAT & CCACGTAAGGAACAGAGACCA & SYBER GREEN \\
\hline VE-Cadherin & GTTCACGCATCGGTTGTTC & TCTGCATCCACTGCTGTCA & SYBER GREEN \\
\hline \multicolumn{4}{|l|}{ Arterial-Venous } \\
\hline Hey-2 & CCCCTGCGAGGAGACGA & $\begin{array}{l}\text { ATCTAATCACAGAGCTAGTACTTT } \\
\text { GCCC }\end{array}$ & $\begin{array}{c}\text { CTCCGAGAGCGACATGGACGAGAC } \\
\mathrm{C}\end{array}$ \\
\hline EphrinB1 & GTTCTCGACCCCAACGTGTT & CAGGCTTCCATTGGATGTTGA & $\begin{array}{c}\text { TCACCTGCAATAGGCCAGAGCAGG } \\
\text { AAATAC }\end{array}$ \\
\hline EphrinB2 & СТССТСAACTGTGCСAAACCA & GGTTATCCAGGCCСТCCAAA & $\begin{array}{c}\text { ACCAAGATATCAAATTCACCATCA } \\
\text { AGTTTCAAGAATTC } \\
\end{array}$ \\
\hline EphB4 & GCCGCAGCTTTGGAAGAG & GGGAATGTCACCCACTTCAGA & CCCTGCTGAACACAAAATTGG \\
\hline Dll-4 & ATGACCACTTCGGCCACTATG & GCCCGAAAGACAGATAGGCTG & TCCTGCCTGCCCGGTTGGAC \\
\hline C17 & CGACCTGCTACTCCCGCAT & CGCAGCTTGTCCAGCACA & TGAGCCAGGAGATCACCCGCGA \\
\hline GDF-1 & GAAGCTTCTATGGCCACTCCA & AGCACAAGGATGCCCACATT & $\begin{array}{c}\text { ATCCTCATCGTCTCCTCCTACGCCT } \\
\text { TCC } \\
\end{array}$ \\
\hline Lefty-1 & GACTATGGAGCTCAGGGCGA & CACACTCATAAGCCAGGAAGCC & AAGTGGGCCGAGAACTGGGTGCTG \\
\hline Lefty-2 & CTGGACCTCAGGGACTATGGAG & ACACTCGTAAGCCAGGAAGCC & TCAGGGCGACTGTGACCCTGAAGC \\
\hline Myo1B & ATGGAGTGGATGATGCAGCA & TTCACTCGAGATTCGGGCTT & CGGAATGCCATGCAGATTGTGGG \\
\hline Sema3F & GTGTGGGAACTTCGTCAGGC & CTCGAGTCGCTCAGGCTCC & $\begin{array}{c}\text { CCTACAACCCCATGTGCACCTATGT } \\
\text { GAA }\end{array}$ \\
\hline Jagged-2 & TCATCCCCTTCCAGTTCGC & AGGCTCTTCCAGCGGTCCT & TGGCCGCGCTCCTTTACCCTC \\
\hline ALDH1A1 & GGAGTGTTGAGCGGGCTAAG & СCTCCACATTCCAGTTTGGC & \begin{tabular}{|c} 
CTCTGACCCCAGGAGTCACTCAAG \\
GC \\
\end{tabular} \\
\hline \multicolumn{4}{|l|}{ Notch Pathway } \\
\hline Notch-1 & CCACGGGCGACGTCACCC & TCCACTCTGGCGGGCACG & \begin{tabular}{|c} 
GAAAATATCGACGATTGTCCAGGA \\
AACAA \\
\end{tabular} \\
\hline Notch-2 & CTTGCAGCCCGCTACTCAC & GGTTGCGAATCAGAATCTGGA & ACATGGGCCGCTGTCCACTCCAT \\
\hline Notch-3 & GCCGTGTGCTTCCATGG & CCGGATTTGTGTCACAGATAGC & CCCATGGGCAAGACTGGCCTCC \\
\hline Notch-4 & ATGTCTCAATGGCGGCTCC & GGAGAAGGTGCCAGGCCT & TGTGTCTGCCCCGTGCTTCAATG \\
\hline Jagged-1 & CCAATGACTGCAGCCCTCAT & GCTCCAAAGGCACAAGGTGA & $\begin{array}{c}\text { ATGGAGACAACTGGTACCGGTGCG } \\
\mathrm{A}\end{array}$ \\
\hline Jagged-2 & TCATCCCCTTCCAGTTCGC & AGGCTCTTCCAGCGGTCCT & TGGCCGCGCTCCTTTACCCTC \\
\hline Dll-1 & TTGAAGCTCTCCACACAGATTCTC & CTCGCCCACCGTCAGGT & \begin{tabular}{|c} 
TGACCTCGCAACAGAAAACCCAGA \\
AAGACT \\
\end{tabular} \\
\hline Dll-3 & CTGATCTCCCACTGCCCG & TССТААСТССТСТСТССAGGTTTC & CGGCCTCTTGCAGGTGCCCTT \\
\hline Dll-4 & ATGACCACTTCGGCCACTATG & GCCCGAAAGACAGATAGGCTG & TCCTGCCTGCCCGGTTGGAC \\
\hline \multicolumn{4}{|l|}{ Shh Pathway } \\
\hline Patched-1 & CTGCCСТCTTCCGATCACA & TATGAGGAGGCCCACAACCA & TCGGGAAGGCTACTGGCCGGA \\
\hline Patched-2 & CAGCTCGAACCGCAGCA & GTTCCAAGTTTGTCTCAATAATGGC & $\begin{array}{c}\text { TCCACTCTGGCTTCGTGCTTACTTC } \\
\text { CA } \\
\end{array}$ \\
\hline Shh & АСТСАСССССААТТАСААССС & GGTCACCCGCAGTTTCACTC & $\begin{array}{c}\text { ATGAAGAAAACACCGGAGCGGAC } \\
\text { AGG } \\
\end{array}$ \\
\hline \multicolumn{4}{|l|}{ Pluripotency } \\
\hline Oct3a & CTTCGGATTTGCCCTTCTCG & CCTTGGAAGCTTAGCCAGGTC & \\
\hline Nanog & $\begin{array}{c}\text { TTGTTGGTTGTGCTAATCTTTGTAG } \\
\mathrm{A} \\
\end{array}$ & $\begin{array}{l}\text { GGTGAAATCAGGGTAAAATCAACT } \\
\text { AAA } \\
\end{array}$ & \\
\hline Rex-1 & Assay on Demand (Applied Biosystems) & & \\
\hline Telomerase & ACGTCGTGGGAGCCAGAA & CGTAGTTGAGCACGCTGAACA & \\
\hline \multicolumn{4}{|l|}{ Smooth muscle } \\
\hline $\begin{array}{l}\text { Smooth muscle } \\
\alpha \text {-actin }\end{array}$ & GCCTTGGTGTGTGACAATGG & CGTCACCCACGTAGCTGTCTT & TCTGTAAGGCCGGCTTTGCTGGG \\
\hline Calponin & TCATCAAGGCCATCACCAAGT & CCCACGTTCACCTTGTTTCC & $\begin{array}{c}\text { TGAAGCCCCACGACATTTTTGAGG } \\
\text { C } \\
\end{array}$ \\
\hline
\end{tabular}




\begin{tabular}{|l|c|c|c|}
\hline Sm22 $\alpha$ & TCTCAGCCAGCCACATCCA & GCGGCTCATGCCATAGGA & TGTAAGGGTGCAGGCGCCGG \\
\hline Hepatocyte & & & \\
\hline HNF1 $\beta$ & TCCCGCAGACTATGCTCATC & CTCCAGTGAGTCCGGGCT & CCAACCTGAGCGCCCTGGCC \\
\hline HNF3 $\beta$ & CTACGCCAACATGAACTCCA & CTCGTACATCTCGCTCATCACC & ACGCACGCAAAGCCGCCC \\
\hline$\alpha$-fetoprotein & GAAGAGCTGGCCTACCTGAA & GACATGCGAAGCCAATATGA & AGGTGGATTCCGCTCCGGGC \\
\hline CK18 & TATGAGGCCCTGCTGAACAT & AGCAACTCCATGCAAACCAT & ACCTACCGCCGCCTGCTAA \\
\hline Neuronal & & & AGGAAGTCTGCTTGCTGAAGAGG \\
\hline Nestin & CAGGAGAAACAGGGCCTACA & GTCTTGGATCTTTGCTCCCA & CAGGAGAAACAGGGCCTACA \\
\hline MAP2 & Assay on Demand (Applied Biosystems) & & \\
\hline Tau & TCCAGTCGAAGATTGGGTCC & AAATAAAAAGATTGAAACCCACAA & TATCACCCACGTCCCTGGCGGA \\
\hline Otx1 & AAGATCAACCTGCCGGAGT & AAGAAGTCCTCTCCAGTGCG & TTCAAGAACCGCCGCGCCA \\
\hline Nurr1 & Assay on Demand (Applied Biosystems) & & \\
\hline Housekeeping & & & \\
\hline GAPDH & TGGTATCGTGGAAGGACTCATGAC & ATGCCAGTGAGCTTCCCGTTCAGC & CCCAGAGACTGTGGATGGCCCC \\
\hline
\end{tabular}




\begin{tabular}{|c|c|c|}
\hline $\begin{array}{c}\text { Endothelial marker/ } \\
\text { functional characteristic }\end{array}$ & \multicolumn{2}{|c|}{$\%$ positive cells } \\
\hline & hAC133-ECs & hMAPC-ECs \\
\hline KDR & $86 \pm 6$ & $96 \pm 5$ \\
\hline Flt-1 & $78 \pm 6$ & $94 \pm 5$ \\
\hline Tie1 & $71 \pm 13$ & $85 \pm 5$ \\
\hline Tie2 & $80 \pm 15$ & $83 \pm 6$ \\
\hline vWF & $57 \pm 8$ & $74 \pm 9$ \\
\hline Ac-LDL uptake & $89 \pm 7$ & $76 \pm 10$ \\
\hline
\end{tabular}

$\%$ of cells ( \pm SEM) showing expression of endothelial markers or the ability to take up AcLDL in endothelial differentiated hAC133 ${ }^{+}$and hMAPC cultures reveals robust differentiation. An average of 5 experiments is shown. 


\begin{tabular}{|ccc|}
\hline Cell dose & $\begin{array}{c}\mathrm{N}^{\circ} \text { of human vimentin } \\
\text { positive cells } / \mathrm{mm}^{2}\end{array}$ & $\mathrm{~N}^{\circ}$ of vessels $/ \mathrm{mm}^{2}$ \\
$0.1 \times 10^{5}$ cells & $330 \pm 57$ & $46 \pm 5$ \\
$0.5 \times 10^{6}$ cells & $1480 \pm 208$ & $171 \pm 22$ \\
$2.5 \times 10^{6}$ cells & $4874 \pm 625$ & $490 \pm 66$ \\
\hline
\end{tabular}

Number of cells expressing human vimentin in animals transplanted with different doses of undifferentiated hMAPCs with the combination of $\mathrm{VEGF}_{165} / \mathrm{Dll}-4 /$ Shh and number of vessel structures $/ \mathrm{mm}^{2}$ in the matrigel 


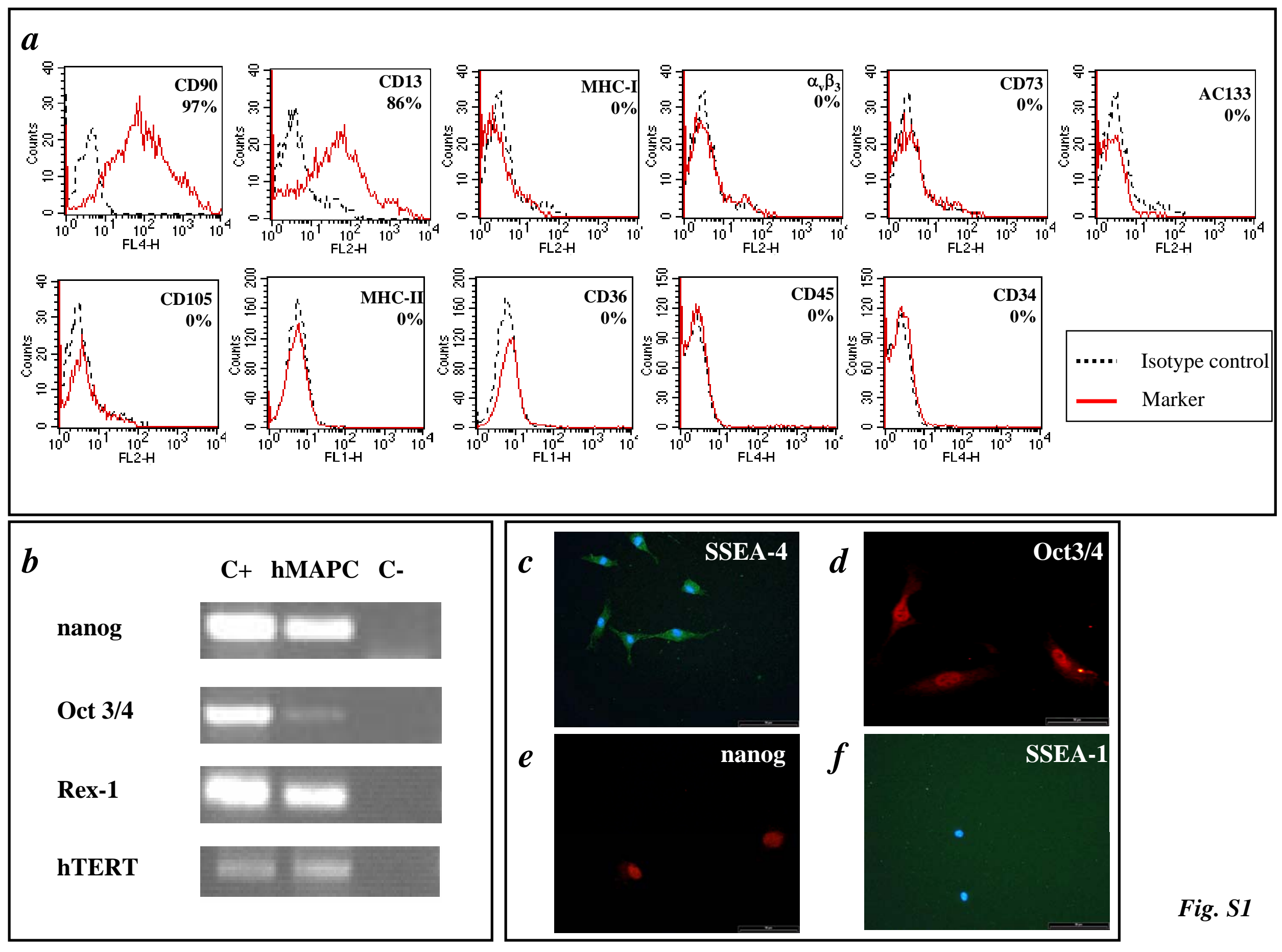



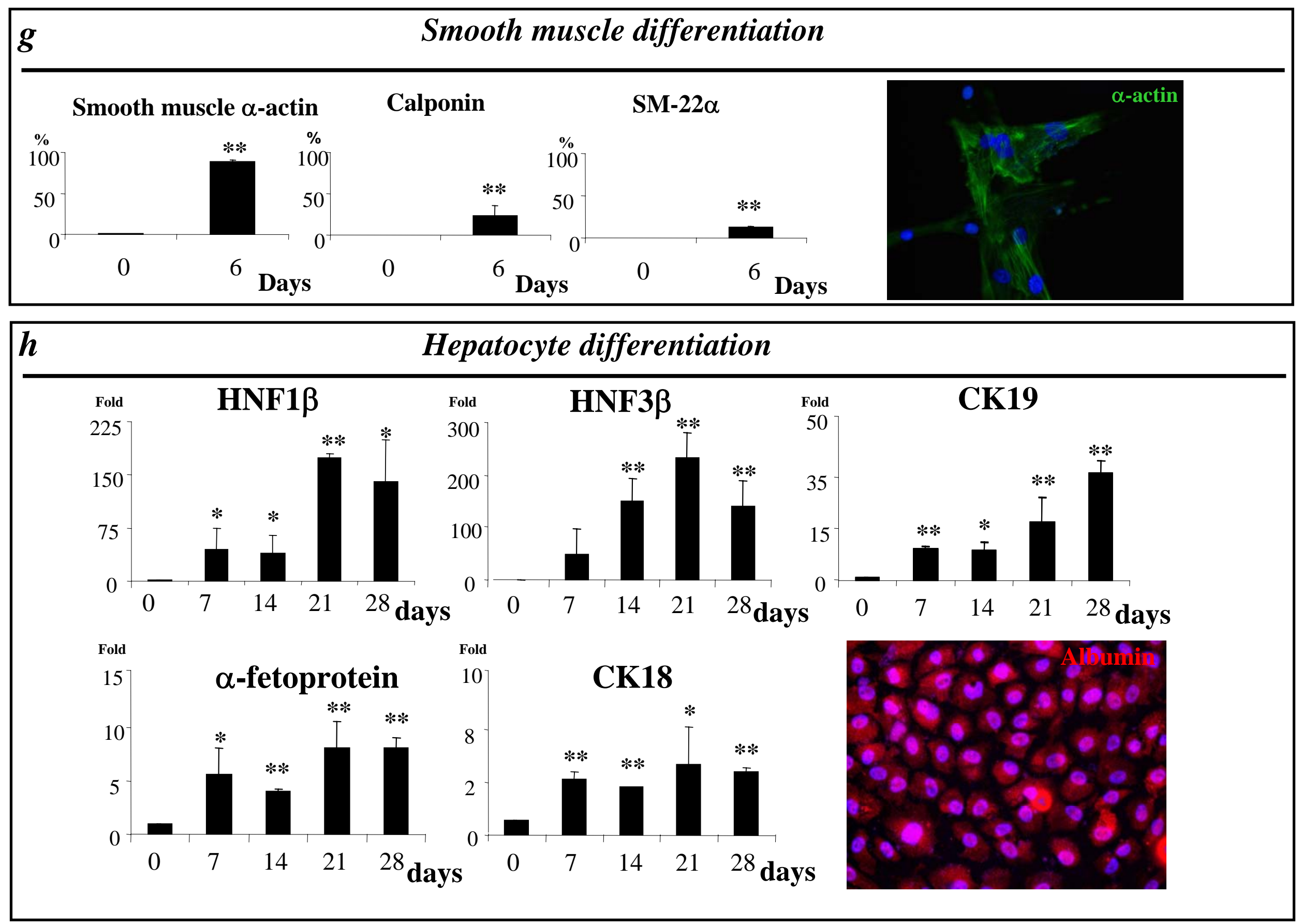


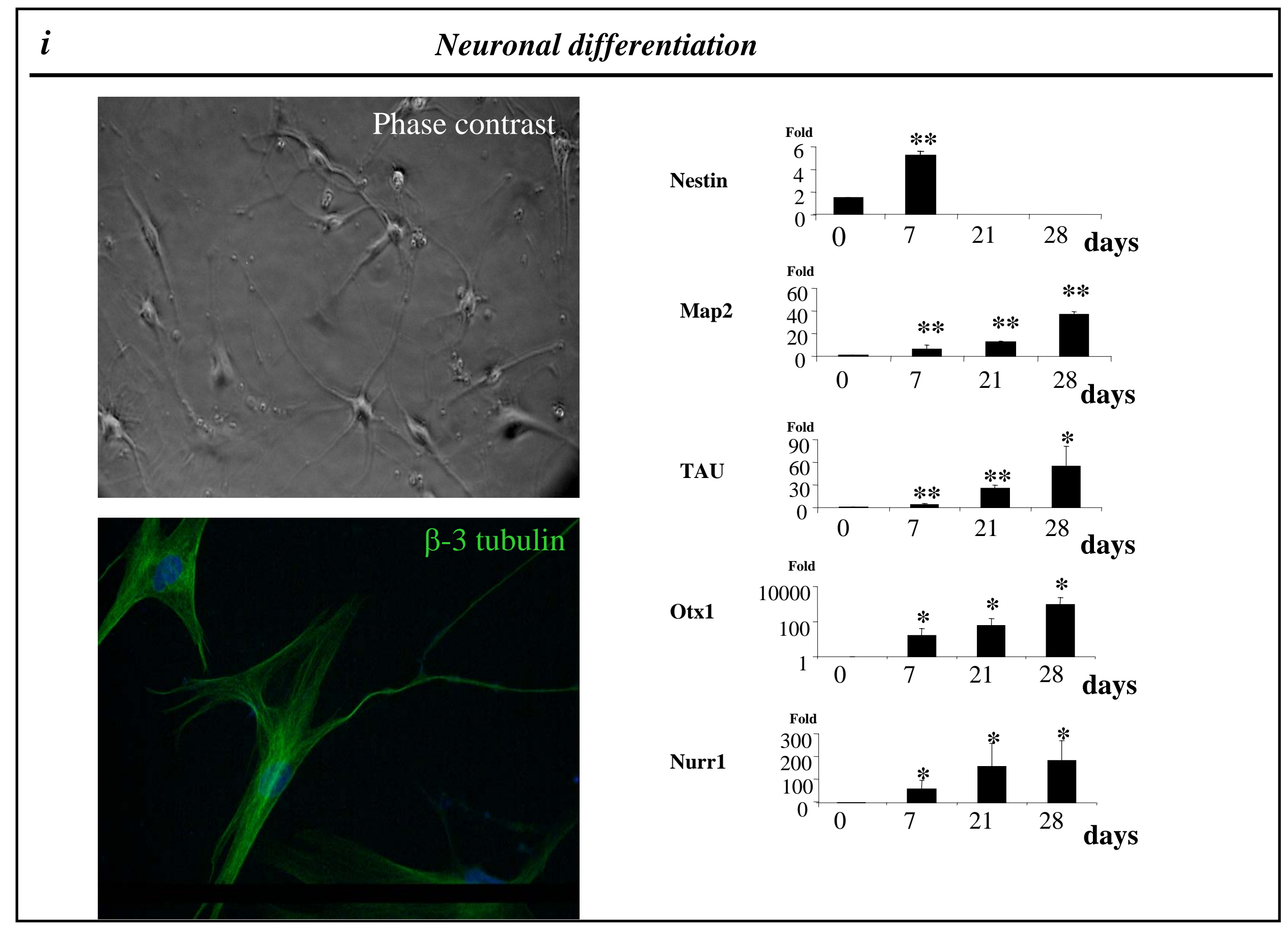



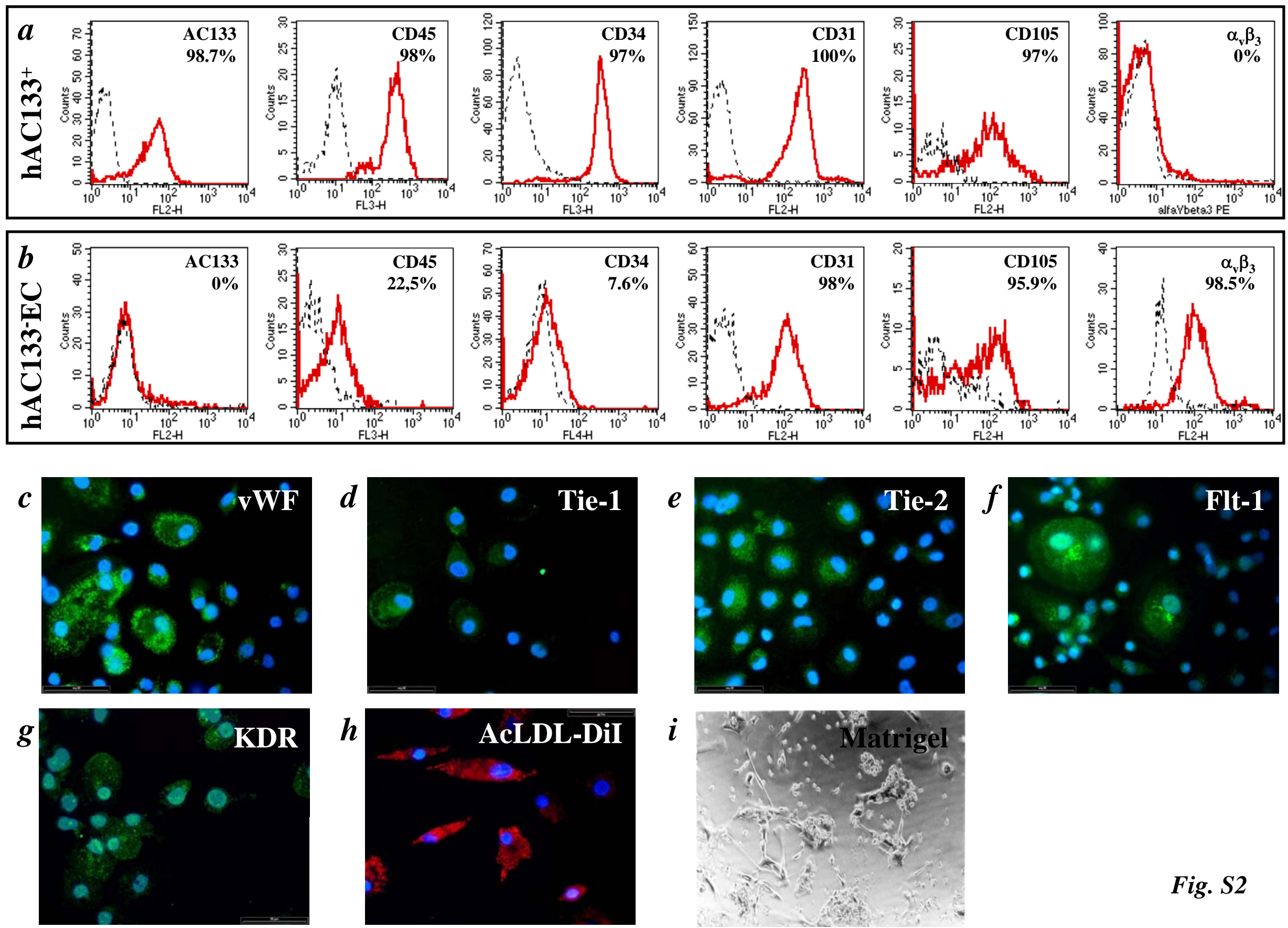

Fig. S2 

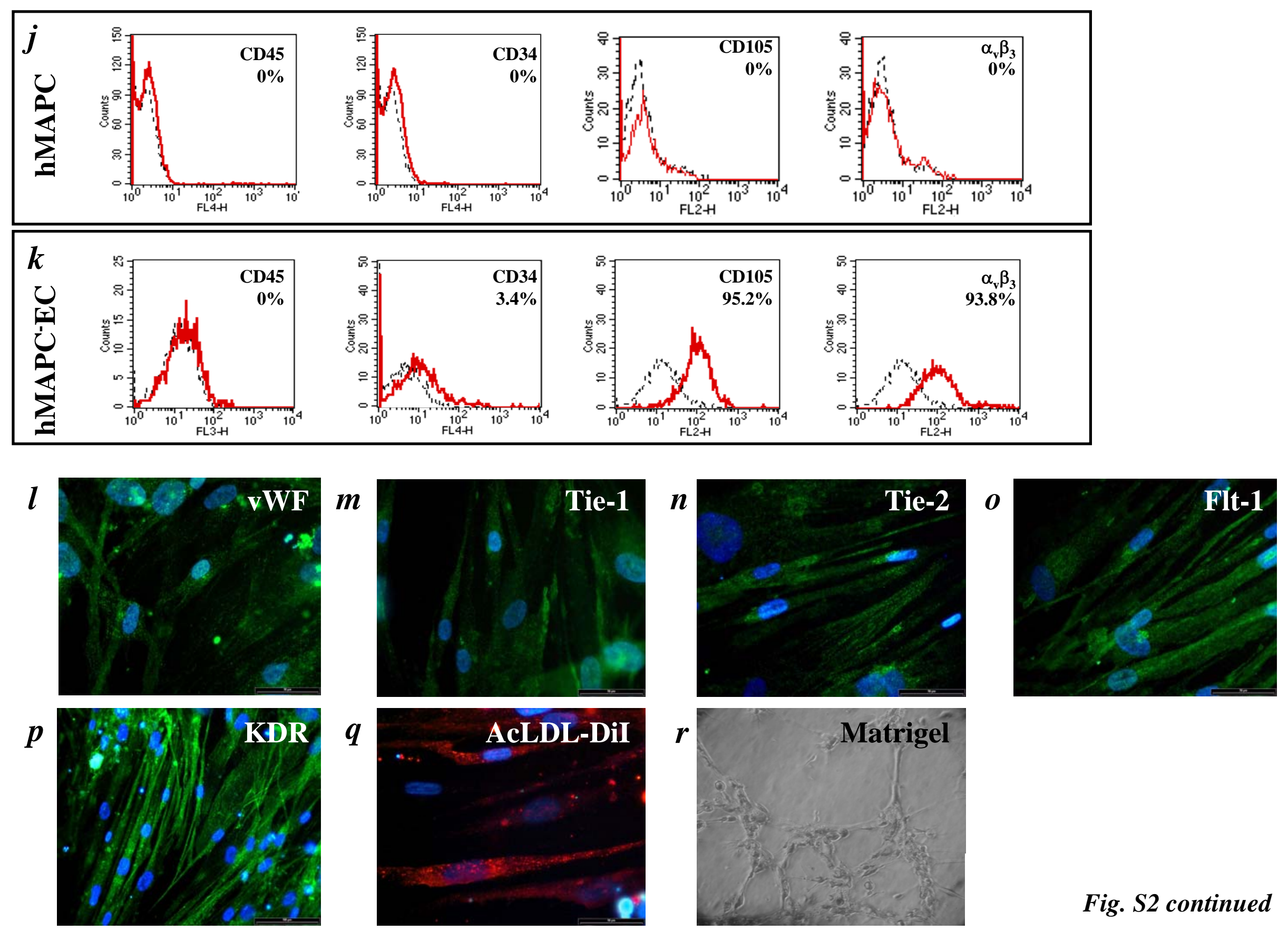

Fig. S2 continued 


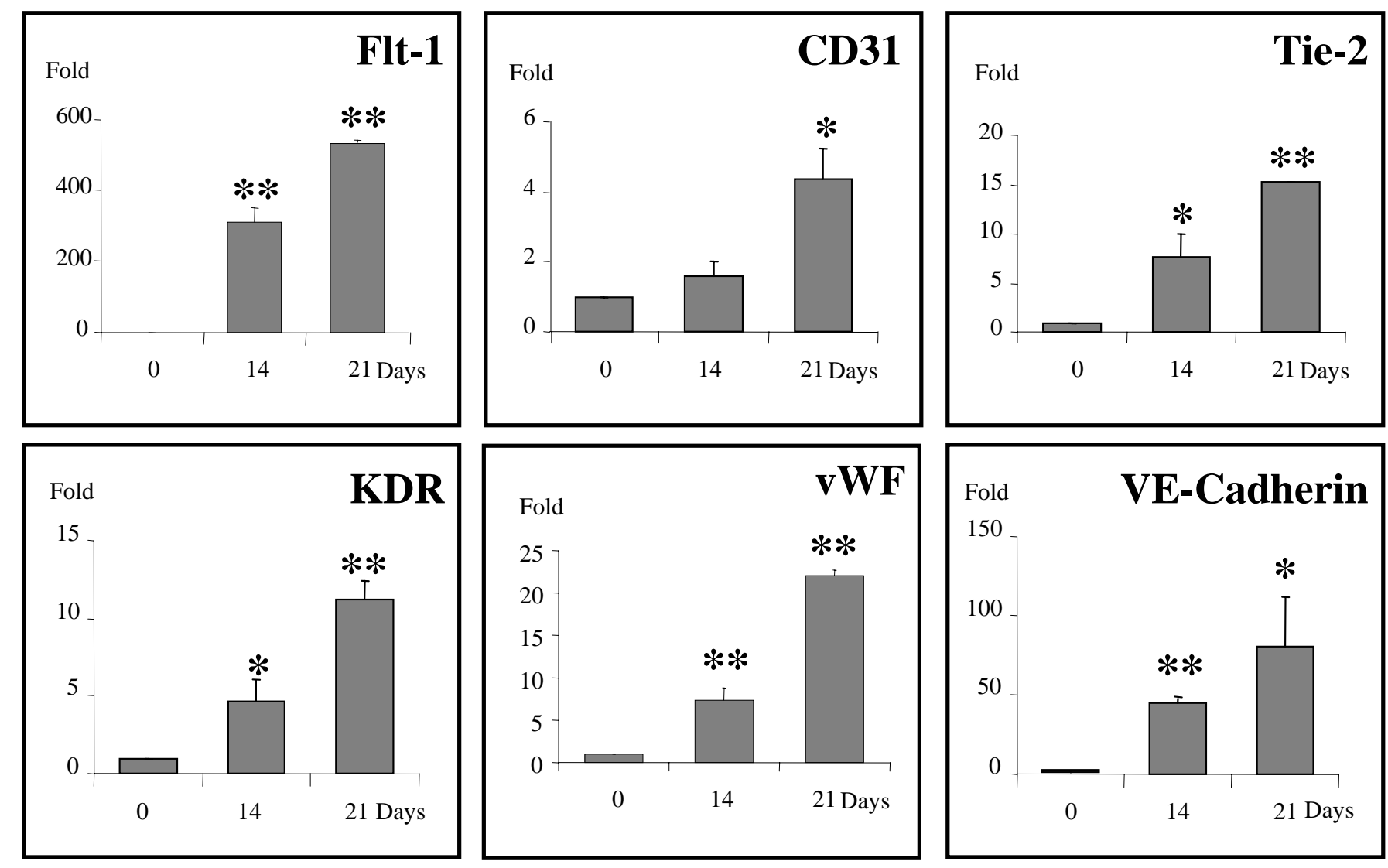

Fig. S3 

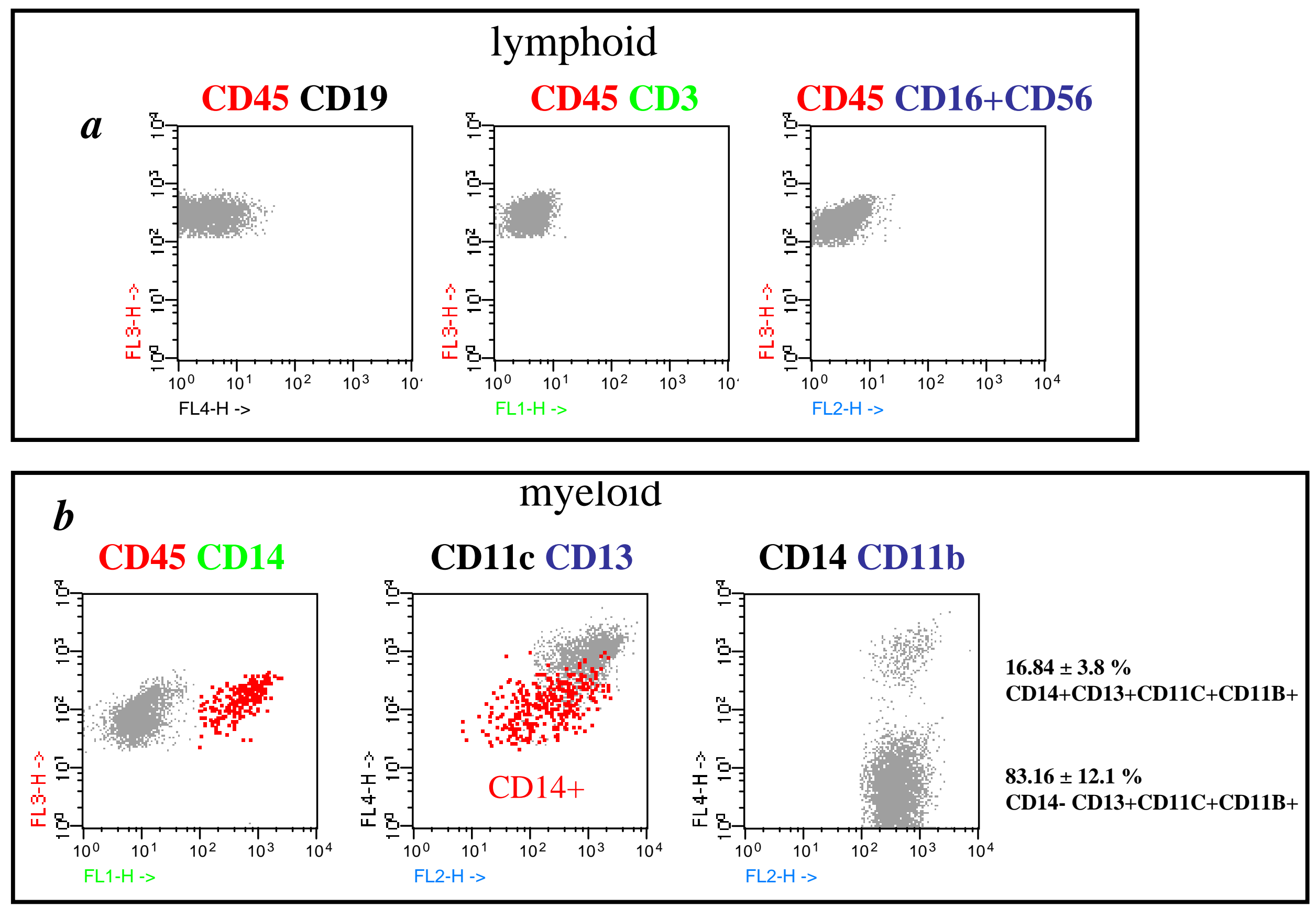

Fig. $S 4$ 


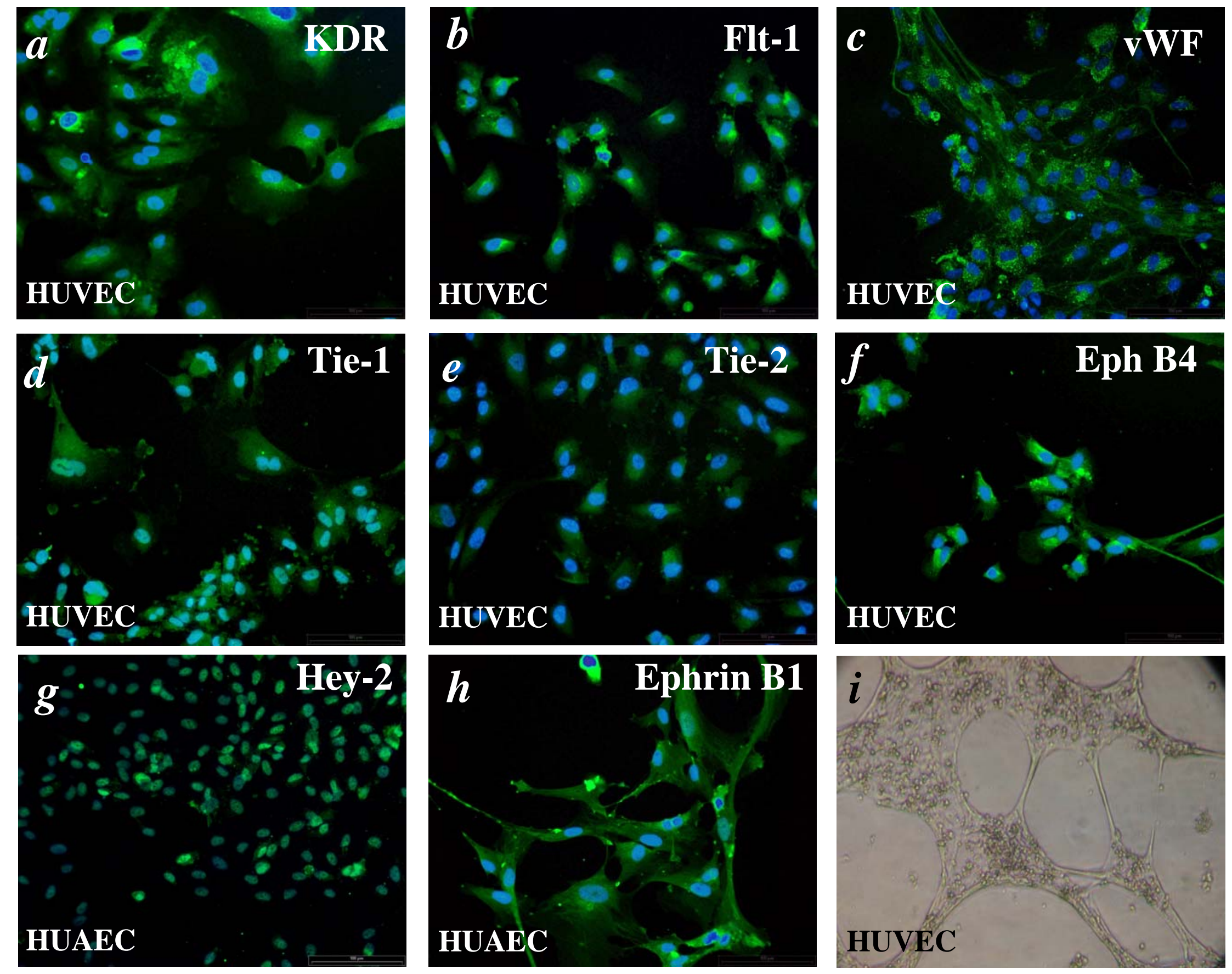

Fig. S5 


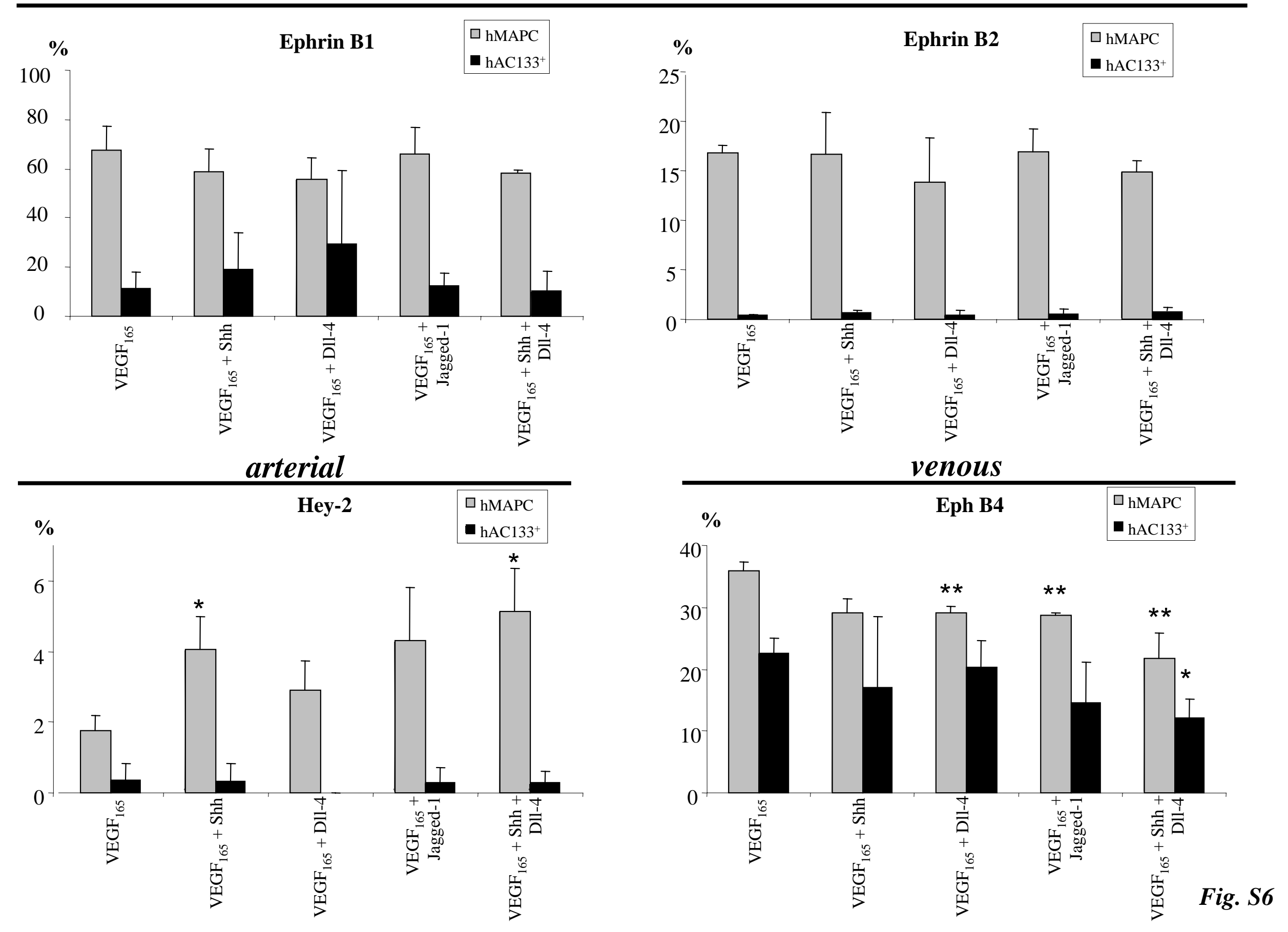




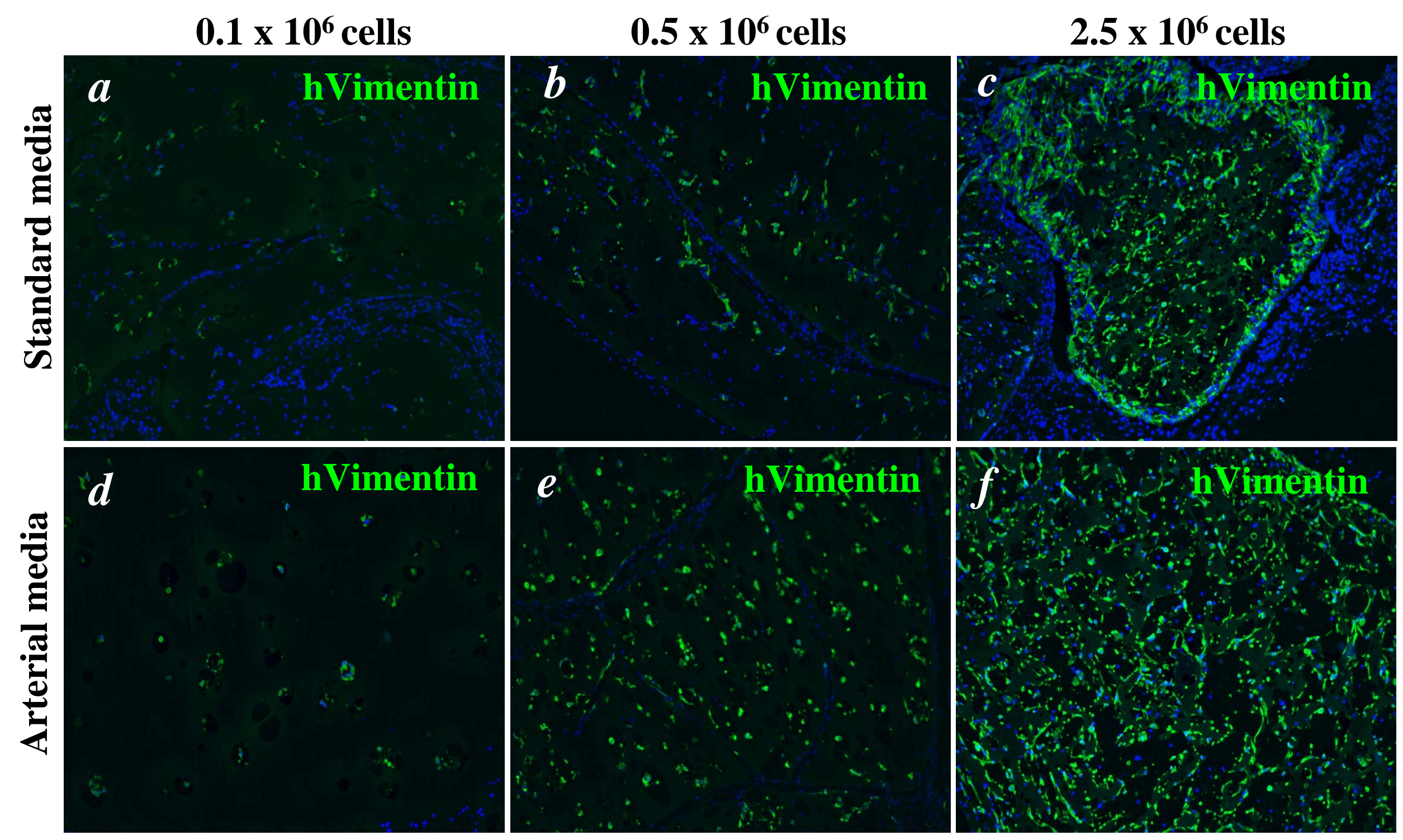

Fig. S7 

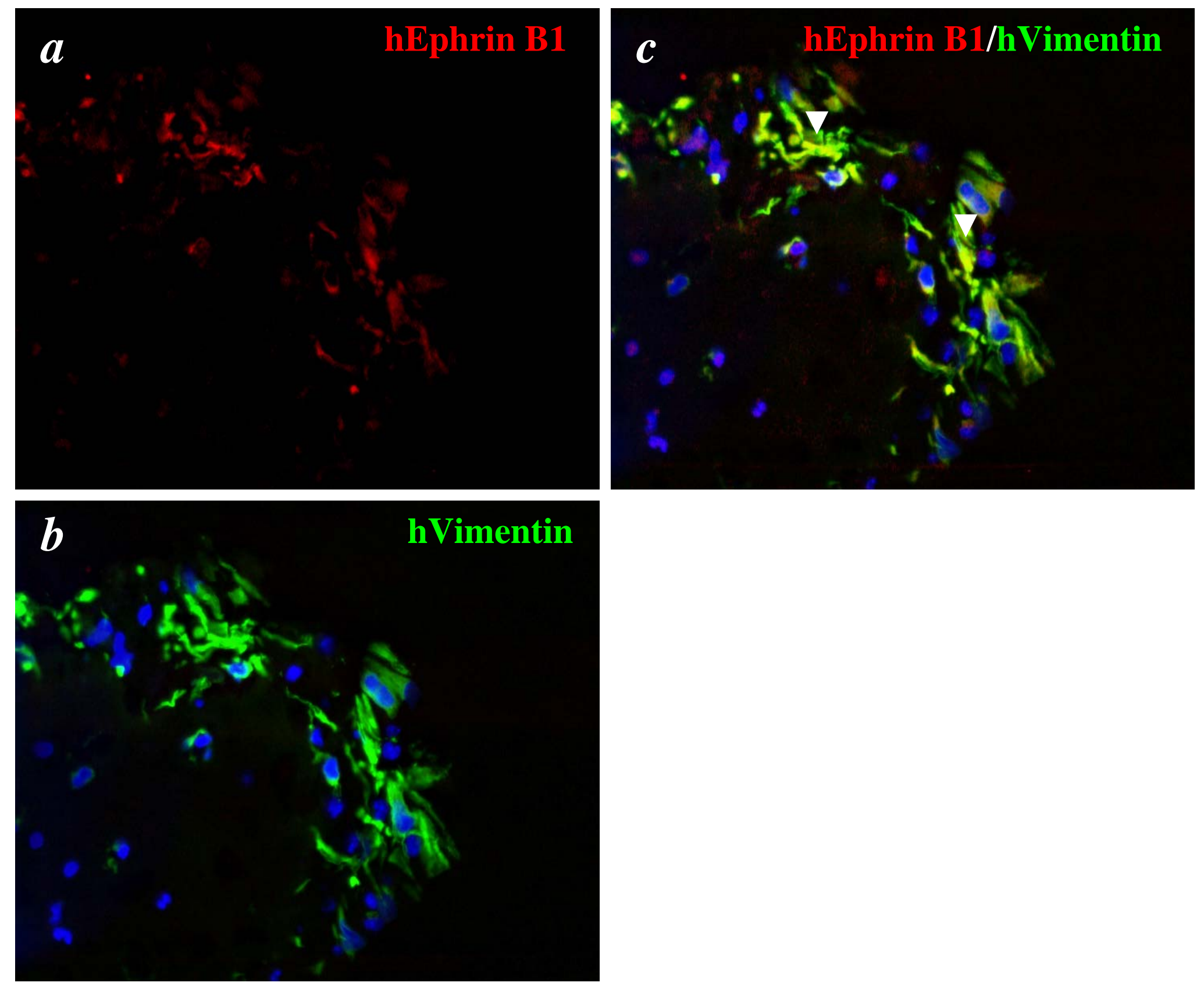


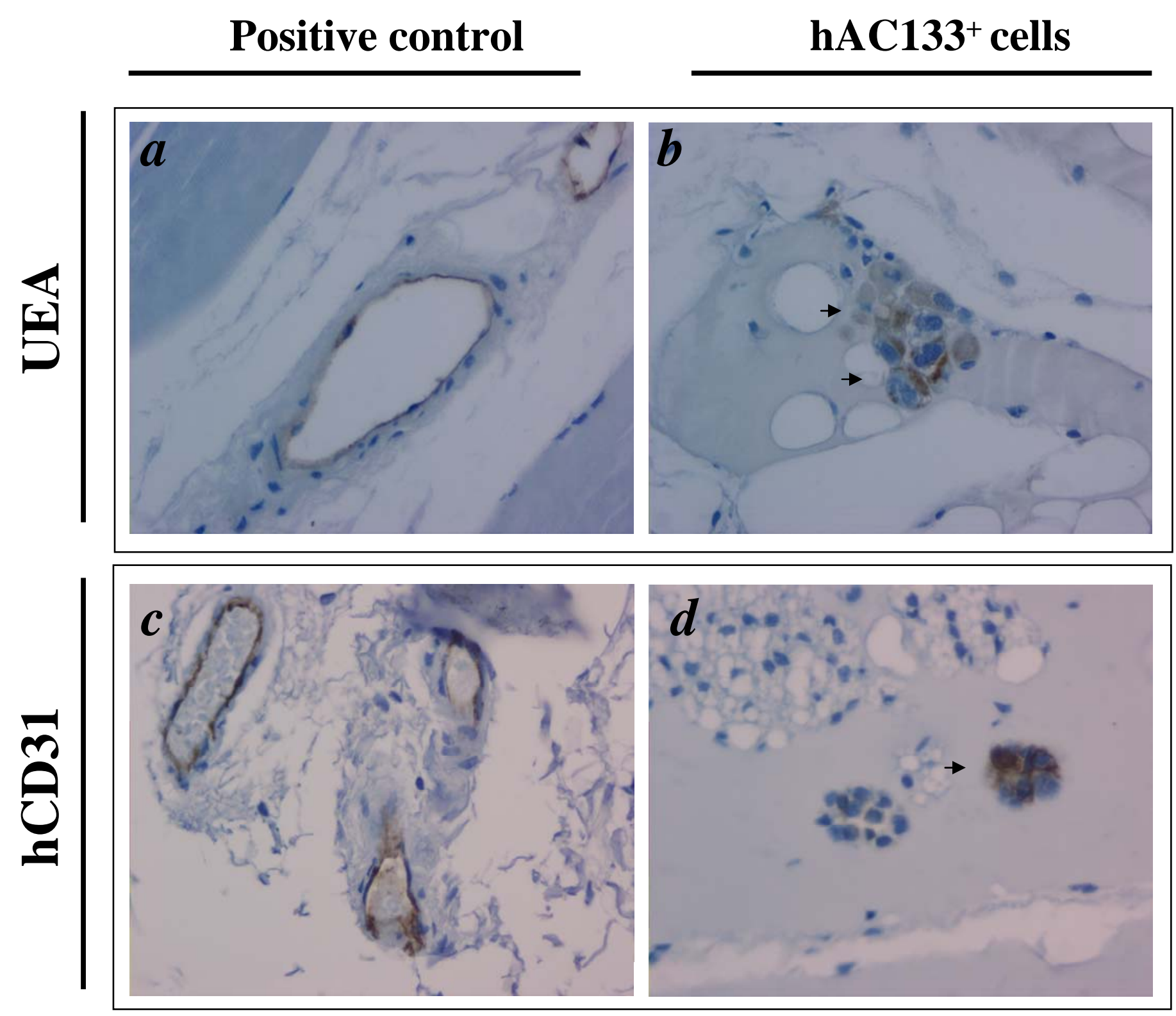

Fig. 59 